\title{
System Characterization Report on the Satellogic NewSat Multispectral Sensor
}

Chapter L of

System Characterization of Earth Observation Sensors

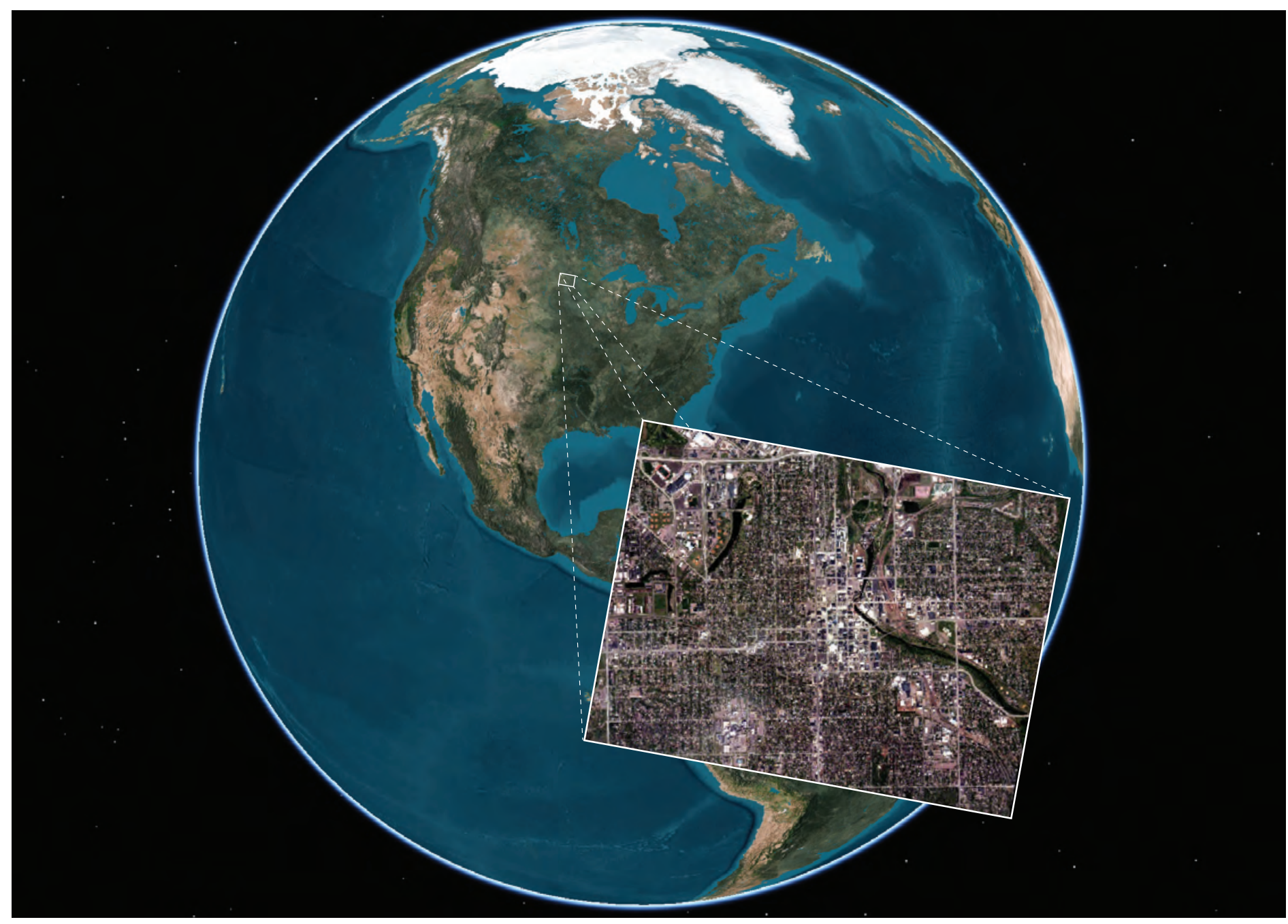

Open-File Report 2021-1030-L

Version 1.1, April 2022

U.S. Department of the Interior

U.S. Geological Survey 
Satellite image of Sioux Falls, South Dakota, captured by the Satellogic NewSat satellite. Image courtesy of Satellogic, used with permission. Image of Earth from Analytical Graphics, Inc., Systems Tool Kit. 


\section{System Characterization Report on the Satellogic NewSat Multispectral Sensor}

By James C. Vrabel, ${ }^{1}$ Paul Bresnahan, ${ }^{2}$ Gregory L. Stensaas, ${ }^{3}$ Cody Anderson, ${ }^{3}$ Jon Christopherson, ${ }^{2}$ Minsu Kim, ${ }^{2}$ and Seonkyung Park ${ }^{2}$

Chapter L of

System Characterization of Earth Observation Sensors

Compiled by Shankar N. Ramaseri Chandra ${ }^{2}$

\footnotetext{
${ }^{1}$ Imaging Technology Consultants, Inc., under contract to the U.S. Geological Survey.

${ }^{2} \mathrm{KBR}$, Inc., under contract to the U.S. Geological Survey.

${ }^{3}$ U.S. Geological Survey.
}

Open-File Report 2021-1030-L

Version 1.1, April 2022

\section{U.S. Department of the Interior}

U.S. Geological Survey 


\section{U.S. Geological Survey, Reston, Virginia: 2022 First Release: 2022 \\ Revised: April 2022 (ver. 1.1)}

For more information on the USGS - the Federal source for science about the Earth, its natural and living resources, natural hazards, and the environment—visit https://www.usgs.gov or call 1-888-ASK-USGS.

For an overview of USGS information products, including maps, imagery, and publications, visit https://store.usgs.gov/.

Any use of trade, firm, or product names is for descriptive purposes only and does not imply endorsement by the U.S. Government.

Although this information product, for the most part, is in the public domain, it also may contain copyrighted materials as noted in the text. Permission to reproduce copyrighted items must be secured from the copyright owner.

Suggested citation:

Vrabel, J.C., Bresnahan, P., Stensaas, G.L., Anderson, C., Christopherson, J., Kim, M., and Park, S., 2022, System characterization report on the Satellogic NewSat multispectral sensor (ver. 1.1, April 2022), chap. L of Ramaseri Chandra, S.N., comp., System characterization of Earth observation sensors: U.S. Geological Survey Open-File Report 2021-1030, 28 p., https://doi.org/10.3133/ofr20211030L.

ISSN 2331-1258 (online) 


\section{Contents}

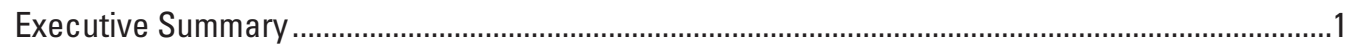

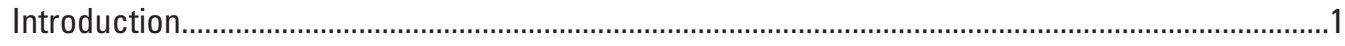

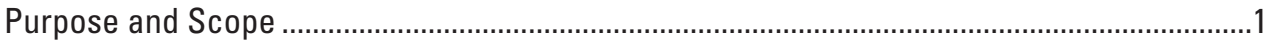

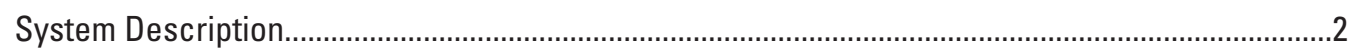

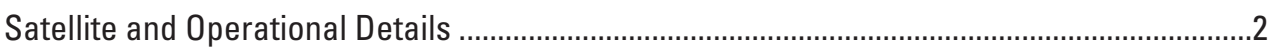

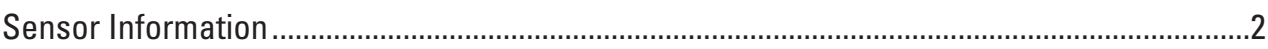

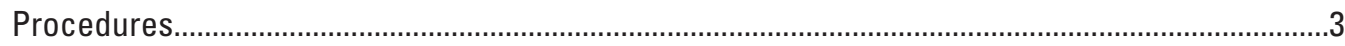

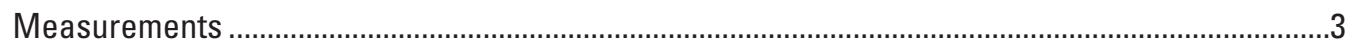

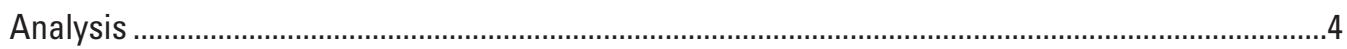

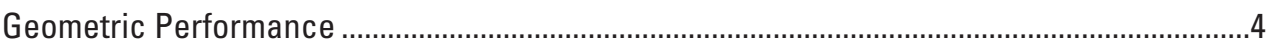

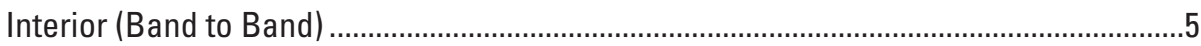

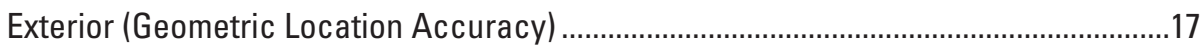

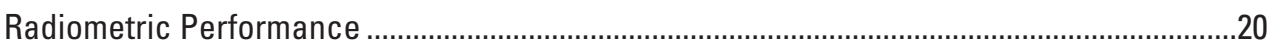

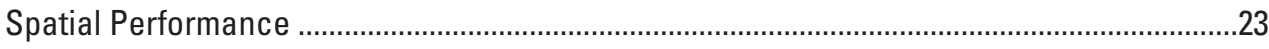

Summary and Conclusions.....................................................................................................

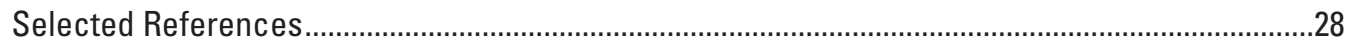

\section{Figures}

1. Graph showing Satellogic's NewSat relative spectral response .......................................

2. Band 1 to band 2 geometric error map, Fès, Morocco......................................................

3. Band 1 to band 2 geometric error histogram, Fès, Morocco .............................................

4. Band 1 to band 2 geometric error plot, Fès, Morocco......................................................

5. Band 2 to band 3 geometric error map, Fès, Morocco....................................................

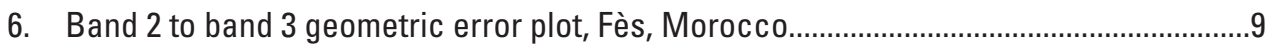

7. Band 2 to band 4 geometric error map, Fès, Morocco.....................................................10

8. Band 2 to band 4 geometric error plot, Fès, Morocco.......................................................11

9. Band 1 to band 2 geometric error map, Railroad Valley, Nevada....................................12

10. Band 1 to band 2 geometric error histogram, Railroad Valley, Nevada ...........................13

11. Band 1 to band 2 geometric error plot, Railroad Valley, Nevada......................................13

12. Band 2 to band 3 geometric error map, Railroad Valley, Nevada...................................... 14

13. Band 2 to band 3 geometric error plot, Railroad Valley, Nevada......................................... 15

14. Band 2 to band 4 geometric error map, Railroad Valley, Nevada...................................... 16

15. Band 2 to band 4 geometric error plot, Railroad Valley, Nevada.......................................17

16. Map showing relative geometric error comparison for Satellogic's NewSat and Sentinel-2, Fès, Morocco …………..........................................................................18

17. Map showing relative geometric error comparison for Satellogic's NewSat and Sentinel-2, Railroad Valley, Nevada ............................................................................19

18. Satellogic's NewSat geometric error plot showing horizontal geolocation accuracy, Sioux Falls, South Dakota ................................................................................20

19. Graphs showing Top of Atmosphere reflectance comparison for Sentinel-2 and Satellogic's NewSat images, Fès, Morocco 
20. Graphs showing Top of Atmosphere reflectance comparison for Sentinel-2 and Satellogic's NewSat images, Railroad Valley, Nevada.

21. Satellogic NewSat image of calibration site at Baotou, China........................................23

22. Graphs showing band 1 raw edge transects and shifted transects at Baotou, China ...24

23. Graphs showing band 1 edge spread function and line spread function and modulation transfer function at Baotou, China.

24. Graphs showing band 2 raw edge transects and shifted transects at Baotou, China ...25

25. Graphs showing band 2 edge spread function and line spread function and modulation transfer function at Baotou, China.

26. Graphs showing band 3 raw edge transects and shifted transects at Baotou, China ...26

27. Graphs showing band 3 edge spread function and line spread function and modulation transfer function at Baotou, China.............................................................26

28. Graphs showing band 4 raw edge transects and shifted transects at Baotou, China ...27

29. Graphs showing band 4 edge spread function and line spread function and modulation transfer function at Baotou, China.

\section{Tables}

1. Satellite and operational details for Satellogic's NewSat multispectral sensor ...............2

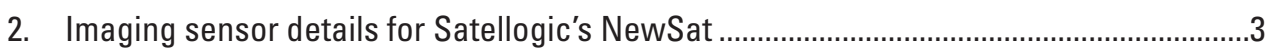

3. U.S. Geological Survey measurement results ............................................................

4. Band-to-band registration error..............................................................................

5. Geometric error of Satellogic's NewSat relative to Sentinel-2 imagery ...........................17

6. Geometric error of Satellogic's NewSat orthorectified image relative to ground control points.............................................................................................................2

7. Top of Atmosphere reflectance comparison for Sentinel-2 against

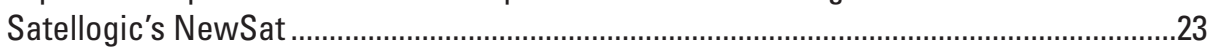

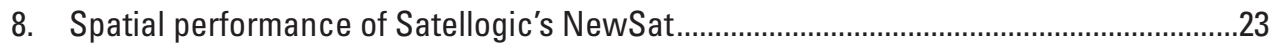

\section{Conversion Factors}

International System of Units to U.S. customary units

\begin{tabular}{|c|c|c|}
\hline Multiply & By & To obtain \\
\hline \multicolumn{3}{|c|}{ Length } \\
\hline centimeter $(\mathrm{cm})$ & 0.3937 & inch (in.) \\
\hline meter $(\mathrm{m})$ & 3.281 & foot $(\mathrm{ft})$ \\
\hline meter $(\mathrm{m})$ & 1.094 & yard (yd) \\
\hline kilometer (km) & 0.6214 & mile (mi) \\
\hline \multicolumn{3}{|c|}{ Mass } \\
\hline kilogram (kg) & 2.205 & pound avoirdupois (lb) \\
\hline
\end{tabular}




\section{Abbreviations}

ECCOE Earth Resources Observation and Science Cal/Val Center of Excellence

GCP ground control point

GSD ground sample distance

JACIE Joint Agency Commercial Imagery Evaluation

USGS U.S. Geological Survey 



\title{
System Characterization Report on the Satellogic NewSat Multispectral Sensor
}

\author{
By James C. Vrabel,, Paul Bresnahan, ${ }^{2}$ Gregory L. Stensaas, ${ }^{3}$ Cody Anderson, ${ }^{3}$ Jon Christopherson, ${ }^{2}$ Minsu \\ Kim, $^{2}$ and Seonkyung Park²
}

\section{Executive Summary}

This report addresses system characterization of Satellogic's NewSat satellite (also known as NuSat) and is part of a series of system characterization reports produced and delivered by the U.S. Geological Survey Earth Resources Observation and Science Cal/Val Center of Excellence. These reports present and detail the methodology and procedures for characterization; present technical and operational information about the specific sensing system being evaluated; and provide a summary of test measurements, data retention practices, data analysis results, and conclusions.

Since 2016, Satellogic has launched 17 NewSat satellites. All NewSat satellites have four-band imagers with a 1-meter (m) ground sample distance, and values in pixels are identical to values in meters. All NewSats have been launched into Sun-synchronous orbits of about 475 kilometers, with inclinations of about 97.5 degrees. The satellites have expected lifetimes of about 3 years. More information on the Satellogic satellites and sensors is available in the "2020 Joint Agency Commercial Imagery EvaluationRemote Sensing Satellite Compendium" and from the manufacturer at https://satellogic.com/.

The Earth Resources Observation and Science Cal/Val Center of Excellence system characterization team completed data analyses to characterize the geometric (interior and exterior), radiometric, and spatial performances. Results of these analyses indicate that the NewSat satellites have an interior geometric performance in the range of -0.119 $(-0.119$ pixel $)$ to $0.020 \mathrm{~m}(0.020$ pixel $)$ in easting and -0.148 $(-0.148$ pixel $)$ to $0.014 \mathrm{~m}(0.014$ pixel $)$ in northing in band-toband registration, an exterior geometric performance of -9.04 ( -9.04 pixels) to $-5.84 \mathrm{~m}$ ( -5.84 pixels) in easting and 1.25 (1.25 pixels) to $3.11 \mathrm{~m}$ (3.11 pixels) in northing offset in comparison to Sentinel-2, an exterior geometric performance using ground control points of a 6.5 -m circular error ( 95 percent),

\footnotetext{
${ }^{1}$ Imaging Technology Consultants, Inc., under contract to the U.S. Geological Survey.

${ }^{2} \mathrm{KBR}$, Inc., under contract to the U.S. Geological Survey.

${ }^{3}$ U.S. Geological Survey.
}

a radiometric performance in the range of 0.034 to 0.081 in offset and 0.652 to 0.808 in slope, and a spatial performance in the range of 1.61 to 1.76 pixels for full width at half maximum, with a modulation transfer function at a Nyquist frequency in the range of 0.081 to 0.138 .

\section{Introduction}

Satellogic is an Argentinian company, founded in 2010, that specializes in building and operating Earth observation satellites. Their small satellites, known as NewSats (or NuSats), have been launched since May 2016. These satellites carry video, multispectral, and hyperspectral sensors. The NewSats are 43 centimeters $(\mathrm{cm})$ x $45 \mathrm{~cm}$ x $75 \mathrm{~cm}$ in size and have a mass of about 37 kilograms. As of August 2021, Satellogic has 17 NewSats in orbit. This assessment focuses on their four-band multispectral sensor, which collects data at a 1-meter (m) spatial resolution. All Satellogic data used in this assessment were provided with permission from Satellogic. More information on the Satellogic satellites and sensors is available in the "2020 Joint Agency Commercial Imagery Evaluation-Remote Sensing Satellite Compendium" (Ramaseri Chandra and others, 2020) and from the manufacturer at https://satellogic.com/.

The data analysis results provided in this report have been derived from approved Joint Agency Commercial Imagery Evaluation (JACIE) processes and procedures. JACIE was formed to leverage resources from several Federal agencies for the characterization of remote sensing data and to share those results across the remote sensing community. More information about JACIE is available at https://www.usgs.gov/corescience-systems/eros/calval/jacie?qt-science_support_page_ related_con $=3 \# q t$-science_support_page_related_con.

\section{Purpose and Scope}

The purpose of this report is to describe the specific sensor or sensing system, test its performance in three categories, complete related data analyses to quantify these performances, and report the results in a standardized document. 
In this chapter, Satellogic's NewSat sensor is described. The performance testing of the system is limited to geometric, radiometric, and spatial qualities. The scope of the geometric assessment is limited to testing the interior alignments of spectral bands against each other. The exterior alignment is tested in reference to Sentinel-2 and in reference to ground control points (GCPs) collected in the Sioux Falls, South Dakota, area.

The USGS Earth Resources Observation and Science $\mathrm{Cal} / \mathrm{Val}$ Center of Excellence (ECCOE) project, and the associated system characterization process used for this assessment, follows the USGS Fundamental Science Practices, which include maintaining data, information, and documentation needed to reproduce and validate the scientific analysis documented in this report. Additional information and guidance about Fundamental Science Practices and related resource information of interest to the public are available at https://www.usgs.gov/about/organization/science-support/ office-science-quality-and-integrity/fundamental-sciencepractices. For additional information related to the report, please contact ECCOE at eccoe@usgs.gov.

\section{System Description}

This section describes the satellite and operational details and provides information about Satellogic's NewSat sensor.

\section{Satellite and Operational Details}

The satellite and operational details for Satellogic's NewSat are listed in table 1.

\section{Sensor Information}

The imaging sensor details for Satellogic's NewSat are listed in table 2. The relative spectral response for Satellogic's NewSat is shown in figure 1.

Table 1. Satellite and operational details for Satellogic's NewSat multispectral sensor.

[TOA, Top of Atmosphere; cm, centimeter; , about; kg, kilogram; MSI, Multispectral Imager; NIR, near infrared; Q3, July-September; km, kilometer; ${ }^{\circ}$, degree; \pm , plus or minus; m, meter]

\begin{tabular}{ll}
\hline \multicolumn{1}{c}{ Product information } & NewSat \\
\hline Product name & Level 1 TOA reflectance \\
\hline Satellite name & Satellogic NewSat (also known as NuSat) \\
\hline Satellite size & Small satellite $(43 \mathrm{~cm} \times 45 \mathrm{~cm} \times 75 \mathrm{~cm})$, mass $\sim 37 \mathrm{~kg}$ \\
\hline Sensor name & MSI \\
\hline Sensor type & Multispectral (blue, green, red, NIR) \\
\hline Mission type & Global land-monitoring mission \\
\hline Launch date & Multiple dates, beginning in May 2016 \\
\hline Number of satellites & 17 (in orbit as of Q3 2021) \\
\hline Expected lifetime & 3 years \\
\hline Operator & Satellogic \\
\hline & \multicolumn{1}{c}{ Operational details } \\
\hline Operating orbit & Sun-synchronous orbit \\
\hline Orbital altitude range & 475 km \\
\hline Sensor angle altitude & $97.5^{\circ}$ inclination \\
\hline Imaging time & $10: 30$ a.m. (local time) \\
\hline Temporal resolution & As much as 4 times per day, depending on latitude \\
\hline Temporal coverage & 2016 to present (2021) \\
\hline Imaging angles & $\pm 25^{\circ}$ \\
\hline Ground sample distance(s) & $1 \mathrm{~m}$ \\
\hline Data licensing & Restricted \\
\hline Data pricing & Limited free data; commercial imagery pricing \\
\hline Website & https://satellogic.com/ \\
\hline
\end{tabular}


Table 2. Imaging sensor details for Satellogic's NewSat.

[ $\mu \mathrm{m}$, micrometer; $\mathrm{m}$, meter; NIR, near infrared]

\begin{tabular}{lcccc}
\hline Spectral band details & \multicolumn{3}{c}{ NewSat } \\
\cline { 2 - 5 } & $\begin{array}{c}\text { Lower band } \\
(\boldsymbol{\mu m})\end{array}$ & $\begin{array}{c}\text { Upper band } \\
(\boldsymbol{\mu m})\end{array}$ & $\begin{array}{c}\text { Radiometric } \\
\text { resolution } \\
(\mathbf{b i t s})\end{array}$ & $\begin{array}{c}\text { Ground sample } \\
\text { distance } \\
(\mathbf{m})\end{array}$ \\
\hline Band 1-blue & 0.40 & 0.51 & 16 & 1 \\
Band 2-green & 0.51 & 0.58 & 16 & 1 \\
Band 3-red & 0.58 & 0.69 & 16 & 1 \\
Band 4-NIR & 0.75 & 0.90 & 16 & 1 \\
\hline
\end{tabular}

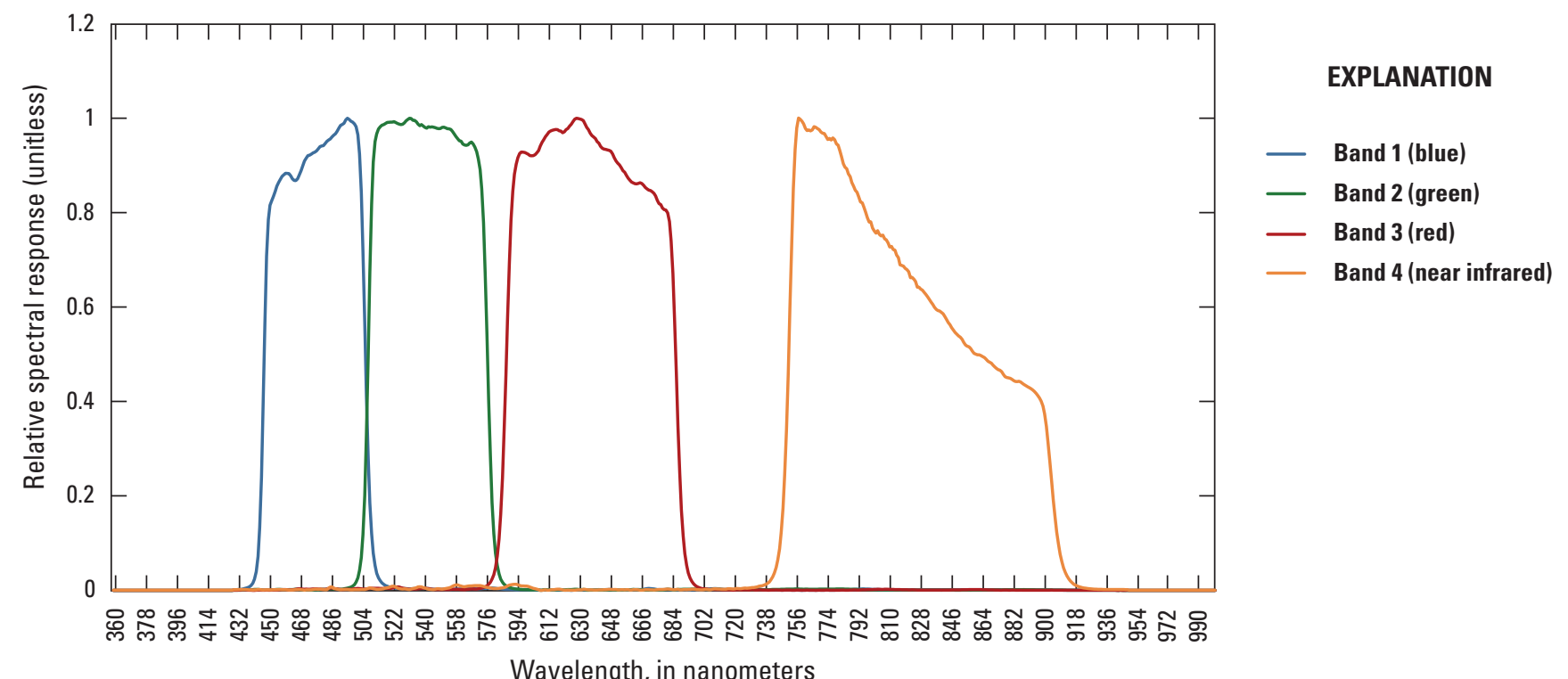

Figure 1. Satellogic's NewSat relative spectral response.

\section{Procedures}

ECCOE has established standard processes to identify Earth observing systems of interest and to assess the geometric, radiometric, and spatial qualities of data products from these systems.

The assessment steps are as follows:

- system identification and investigation to learn the general specifications of the satellite and its sensor(s);

- data receipt and initial inspection to understand the characteristics and any overt flaws in the data product so that it may be further analyzed;

- geometry characterization, including interior geometric orientation measuring the relative alignment of spectral bands and exterior geometric orientation measuring how well the georeferenced pixels within the image are aligned to a known reference;
- radiometry characterization, including assessing how well the data product correlates with a known reference and, when possible, assessing the signal-to-noise ratio; and

- spatial characterization, assessing the two-dimensional fidelity of the image pixels to their projected ground sample distance (GSD).

Data analysis and test results are maintained at the USGS Earth Resources Observation and Science Center by the ECCOE project.

\section{Measurements}

The observed USGS measurements are listed in table 3. Details about the methodologies used are outlined in the "Analysis" section. 
Table 3. U.S. Geological Survey measurement results.

[USGS, U.S. Geological Survey; m, meter; GSD, ground sample distance; RMSE, root mean square error; \%, percent; FWHM, full width at half maximum; RER, relative edge response; MTF, modulation transfer function]

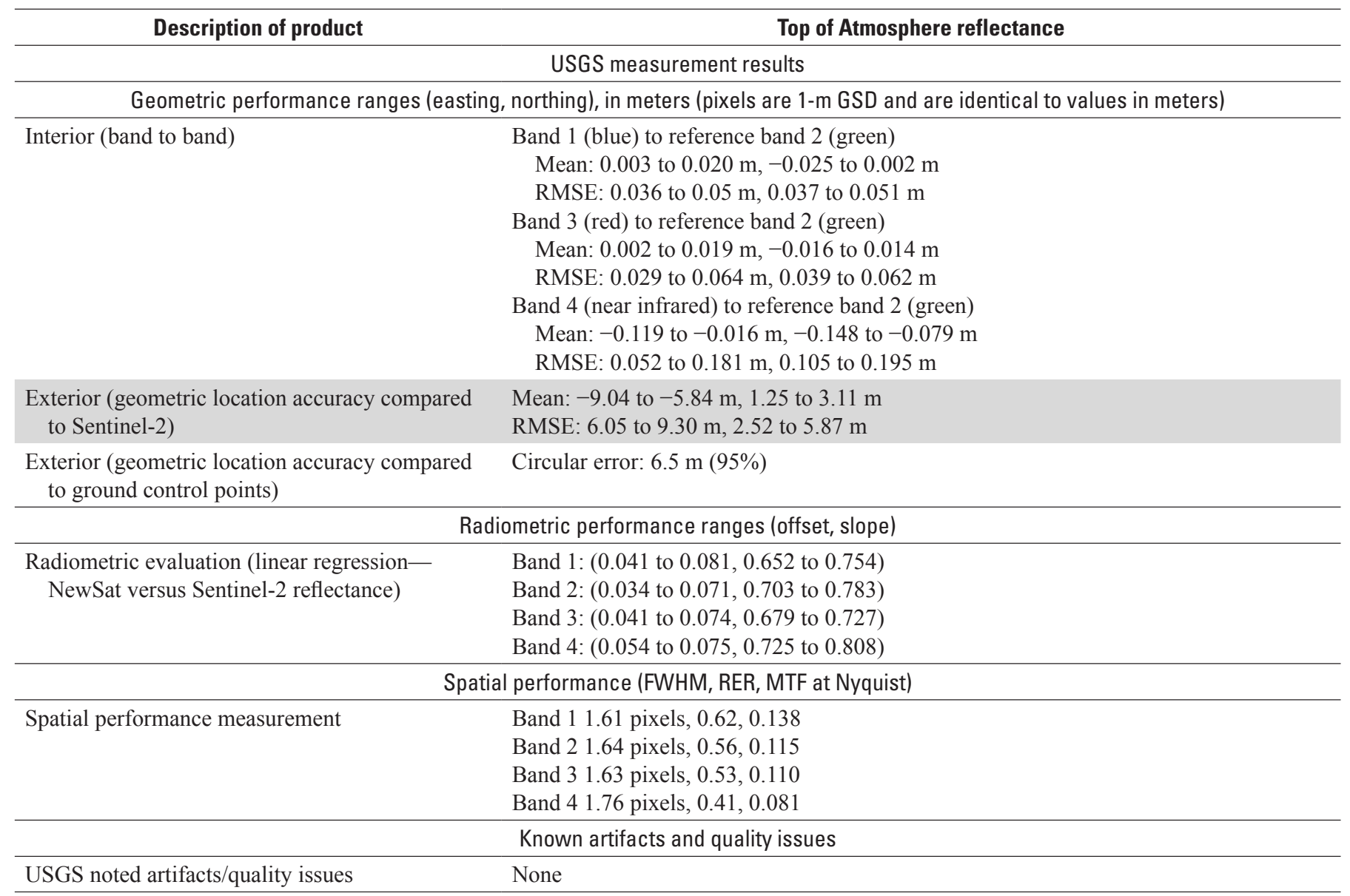

\section{Analysis}

This section of the report describes the geometric, radiometric, and spatial performance of Satellogic's NewSat.

\section{Geometric Performance}

The geometric performance for Satellogic's NewSat is characterized in terms of the interior (band-to-band alignment) and exterior (geometric location accuracy) geometric analysis results. Interior accuracy measures how well the various bands of NewSat are aligned to each other. Exterior accuracy measures the geometric location accuracy of NewSat compared to Sentinel-2 imagery and GCPs. 


\section{Interior (Band to Band)}

The band-to-band alignment analysis was completed using the Earth Resources Observation and Science System Characterization software on two images over Fès, Morocco, and Railroad Valley, Nevada. Band combinations were registered against each other to determine the mean error and root mean square error, as listed in table 4 , with results represented in pixels at a 1-m GSD (values in meters are identical to values in pixels because the sensor has a 1-m GSD). Results of band comparisons to the green band are provided. Geometric error maps for each green band comparison over the two scenes, as well as the corresponding error plots, are shown in figures $2-15$. Geometric error histogram graphs also are shown for the green-to-blue band comparisons for each of the scenes. The geometric error maps indicate the directional shift and relative magnitude of the shift, and the histogram graphs indicate the frequency of observed mean error measurements within the image. The geometric error plots indicate the easting and northing errors between the designated bands. Together, the interior and exterior geometric analysis results, as reported in the "Interior (Band to Band)" and "Exterior (Geometric Location Accuracy)" sections, provide a comprehensive assessment of geometric accuracy.

Table 4. Band-to-band registration error (in pixels).

[ID, identifier; RMSE, root mean square error]

\begin{tabular}{|c|c|c|c|c|c|}
\hline Scene ID & Band combination & $\begin{array}{l}\text { Mean error } \\
\text { (easting) }\end{array}$ & $\begin{array}{l}\text { Mean error } \\
\text { (northing) }\end{array}$ & $\begin{array}{c}\text { RMSE } \\
\text { (easting) }\end{array}$ & $\begin{array}{c}\text { RMSE } \\
\text { (northing) }\end{array}$ \\
\hline \multirow{2}{*}{$\begin{array}{l}\text { 20210423_110441_SN10_L1_Full (Fès, } \\
\text { Morocco) }\end{array}$} & Band 2-band 1 & 0.020 & 0.002 & 0.050 & 0.037 \\
\hline & Band 2-band 4 & -0.119 & -0.148 & 0.181 & 0.195 \\
\hline $\begin{array}{l}\text { 20210228_183201_SN10_L1_Full } \\
\text { (Railroad Valley, Nevada) }\end{array}$ & Band 2-band 1 & 0.003 & -0.025 & 0.036 & 0.051 \\
\hline
\end{tabular}




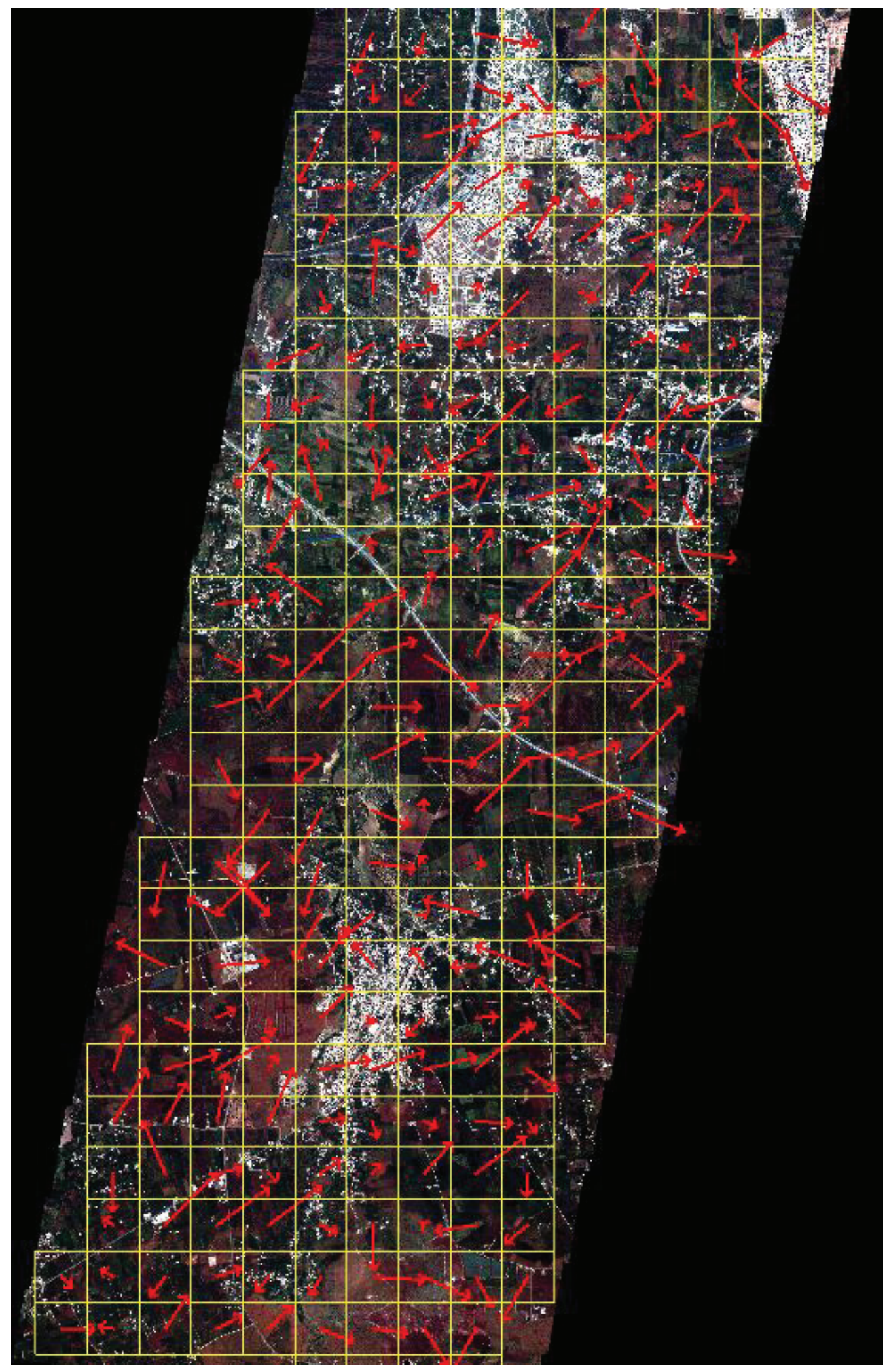

\section{EXPLANATION}

Easting and northing error Grid

Figure 2. Band 1 (blue) to band 2 (green) geometric error map, Fès, Morocco. 

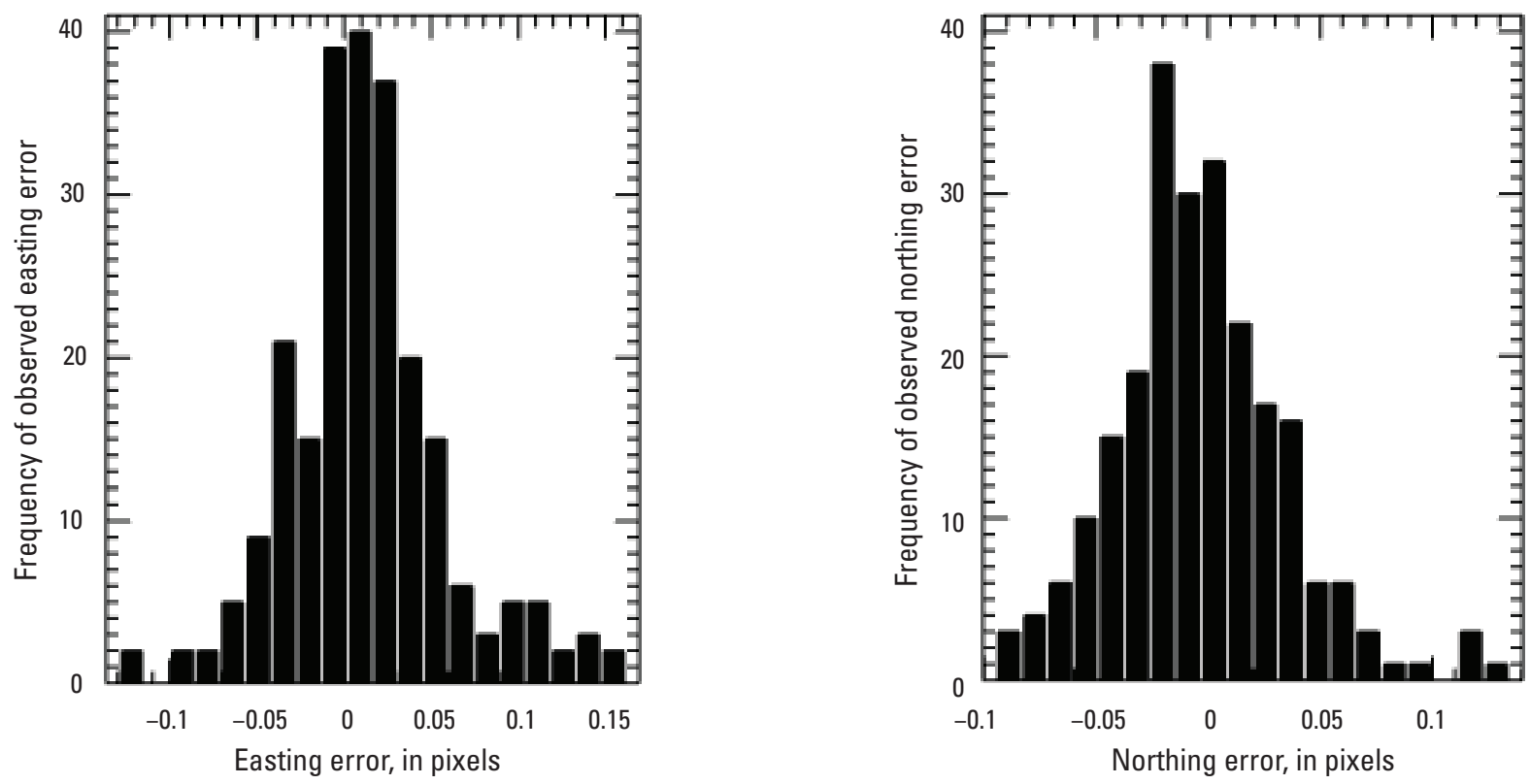

Figure 3. Band 1 (blue) to band 2 (green) geometric error histogram, Fès, Morocco.

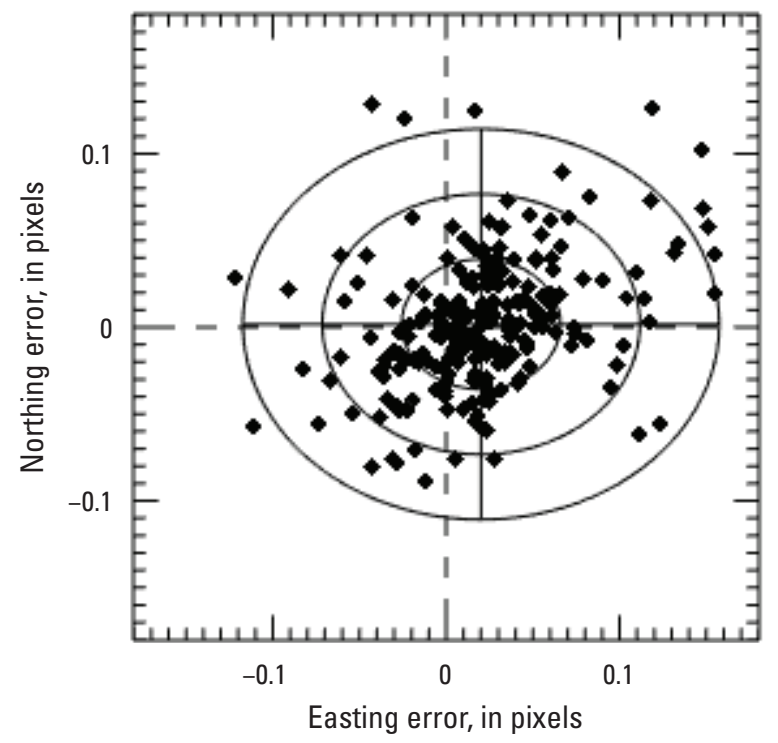

Figure 4. Band 1 (blue) to band 2 (green) geometric error plot, Fès, Morocco. 


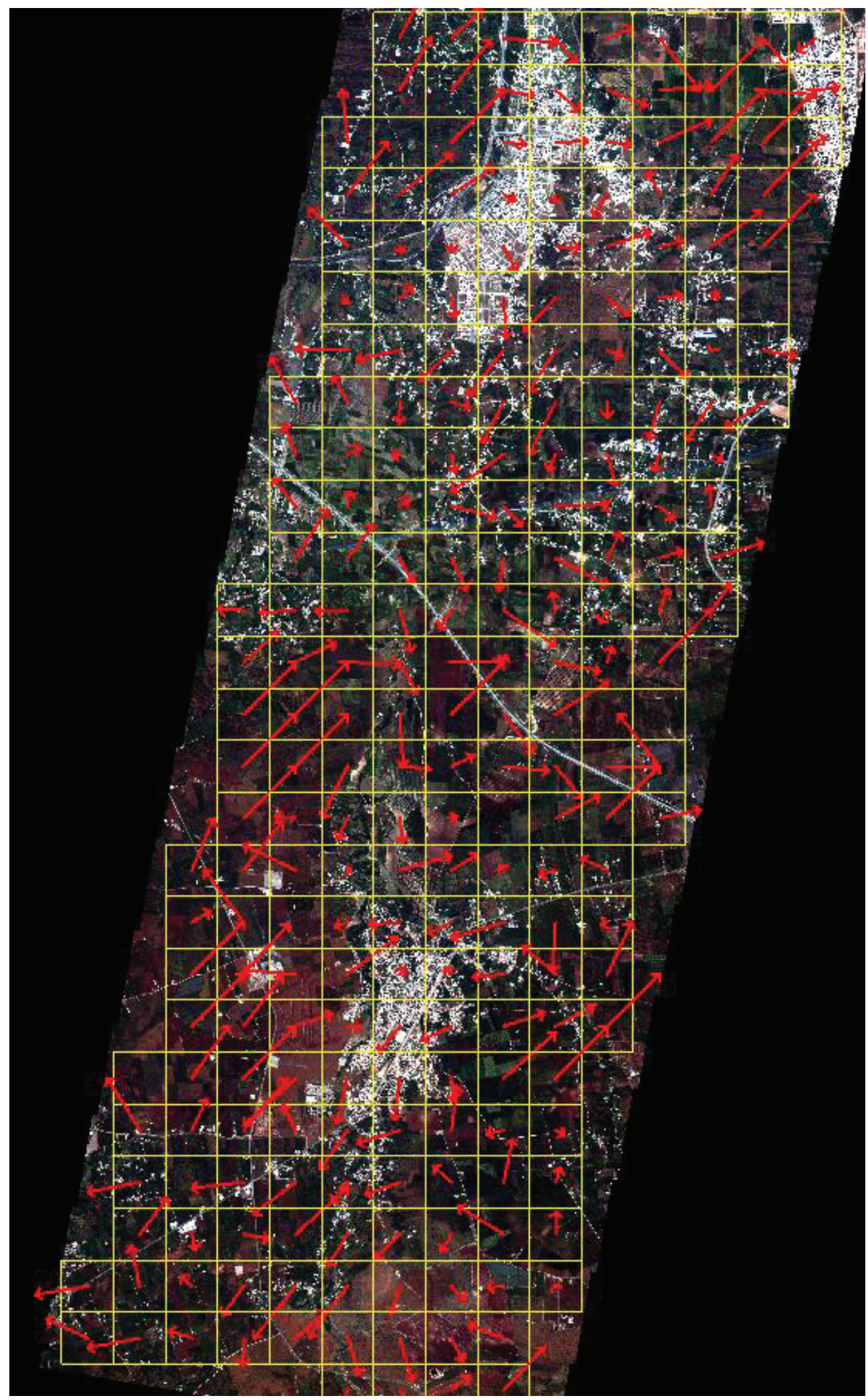

\section{EXPLANATION}

Easting and northing error Grid

Figure 5. Band 2 (green) to band 3 (red) geometric error map, Fès, Morocco. 


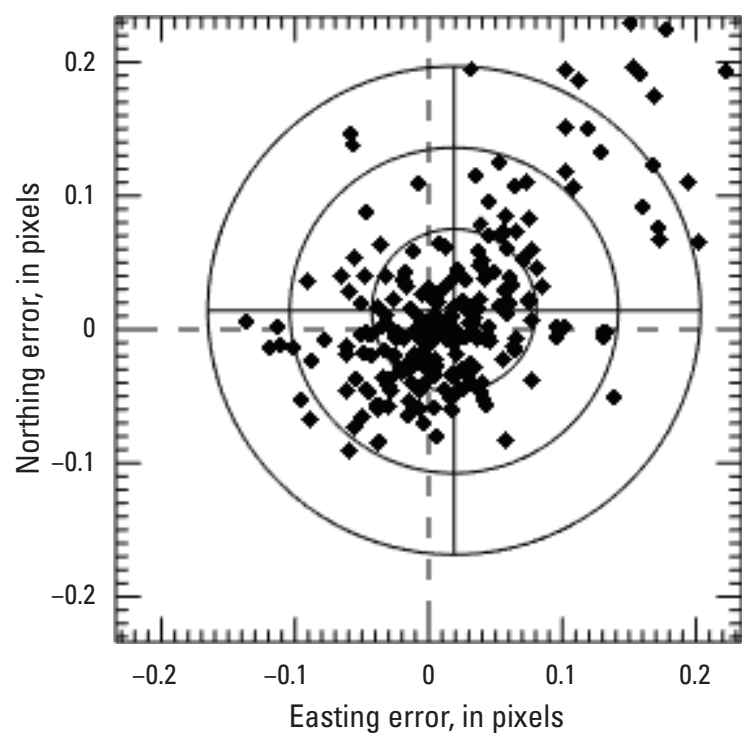

Figure 6. Band 2 (green) to band 3 (red) geometric error plot, Fès, Morocco. 


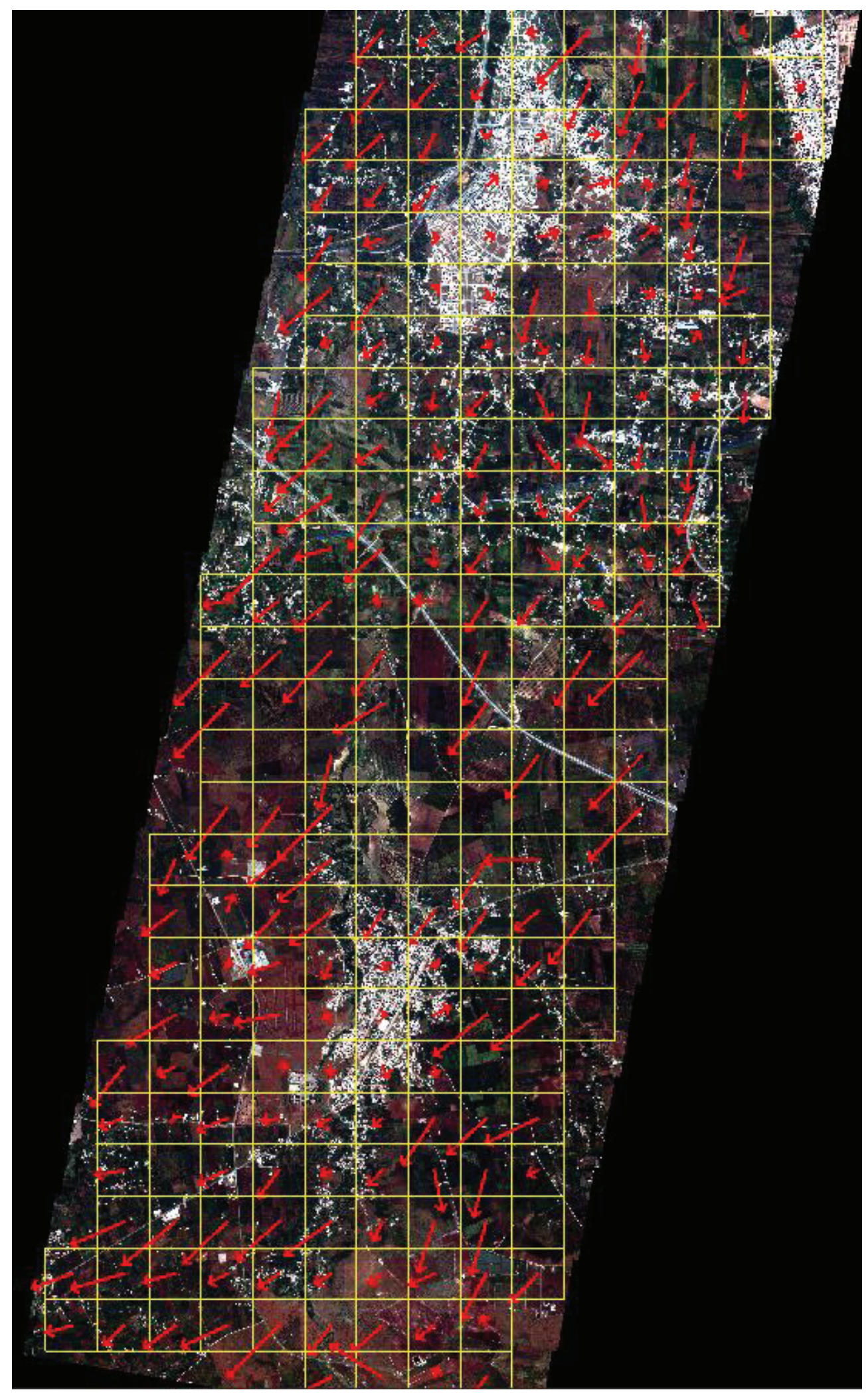

\section{EXPLANATION}

Easting and northing error Grid

Figure 7. Band 2 (green) to band 4 (near infrared) geometric error map, Fès, Morocco. 


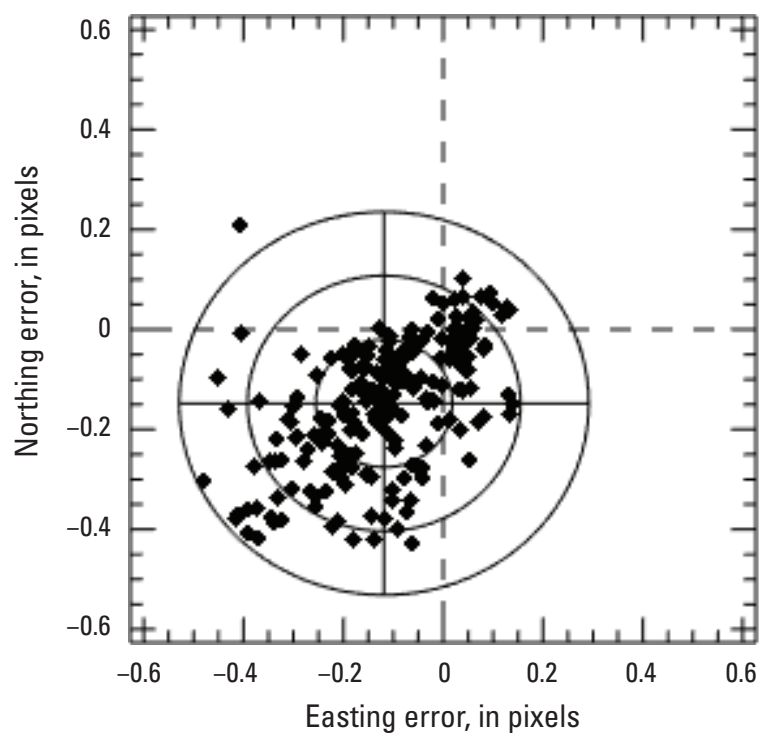

Figure 8. Band 2 (green) to band 4 (near infrared) geometric error plot, Fès, Morocco. 


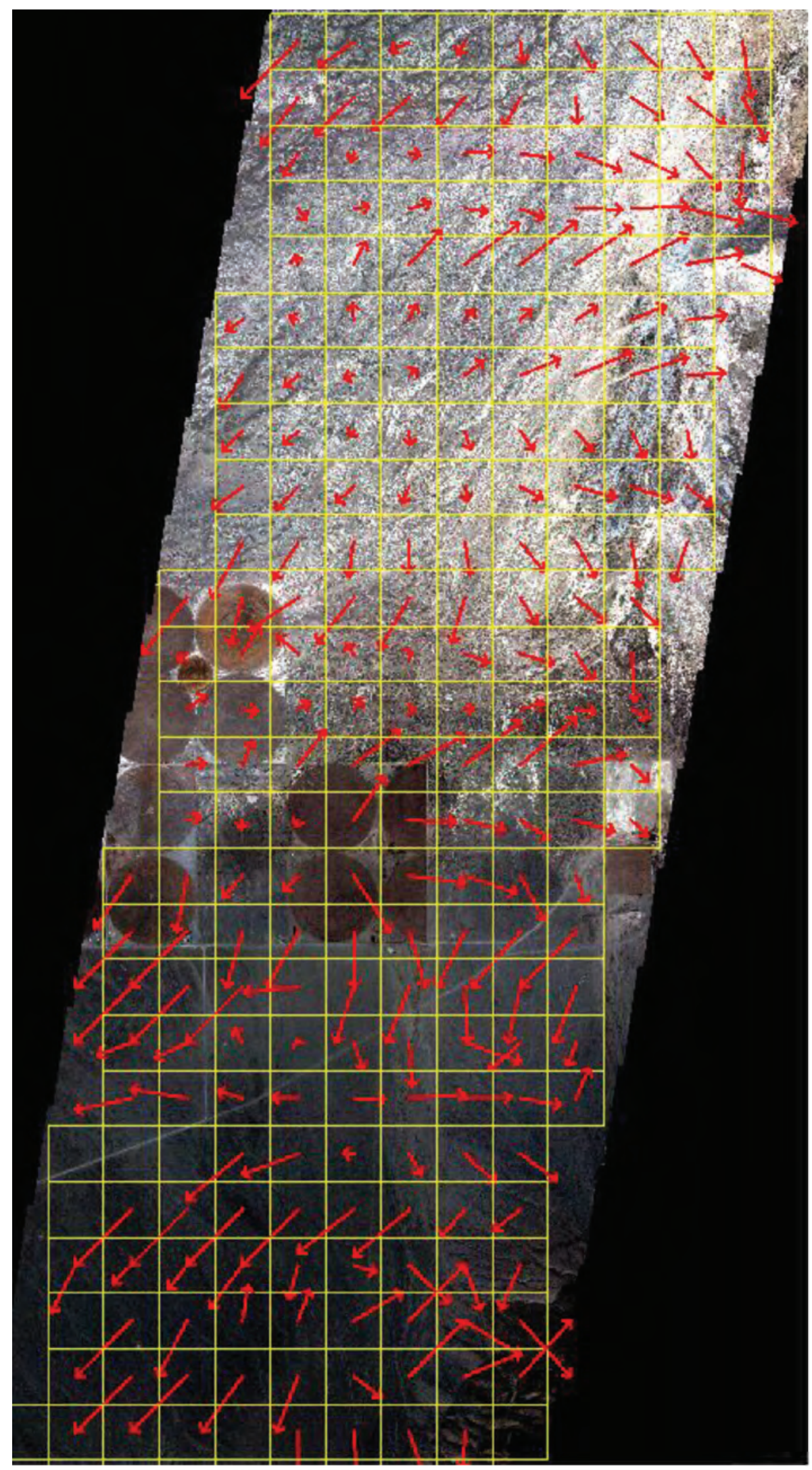

\section{EXPLANATION}

Easting and northing error Grid

Figure 9. Band 1 (blue) to band 2 (green) geometric error map, Railroad Valley, Nevada. 

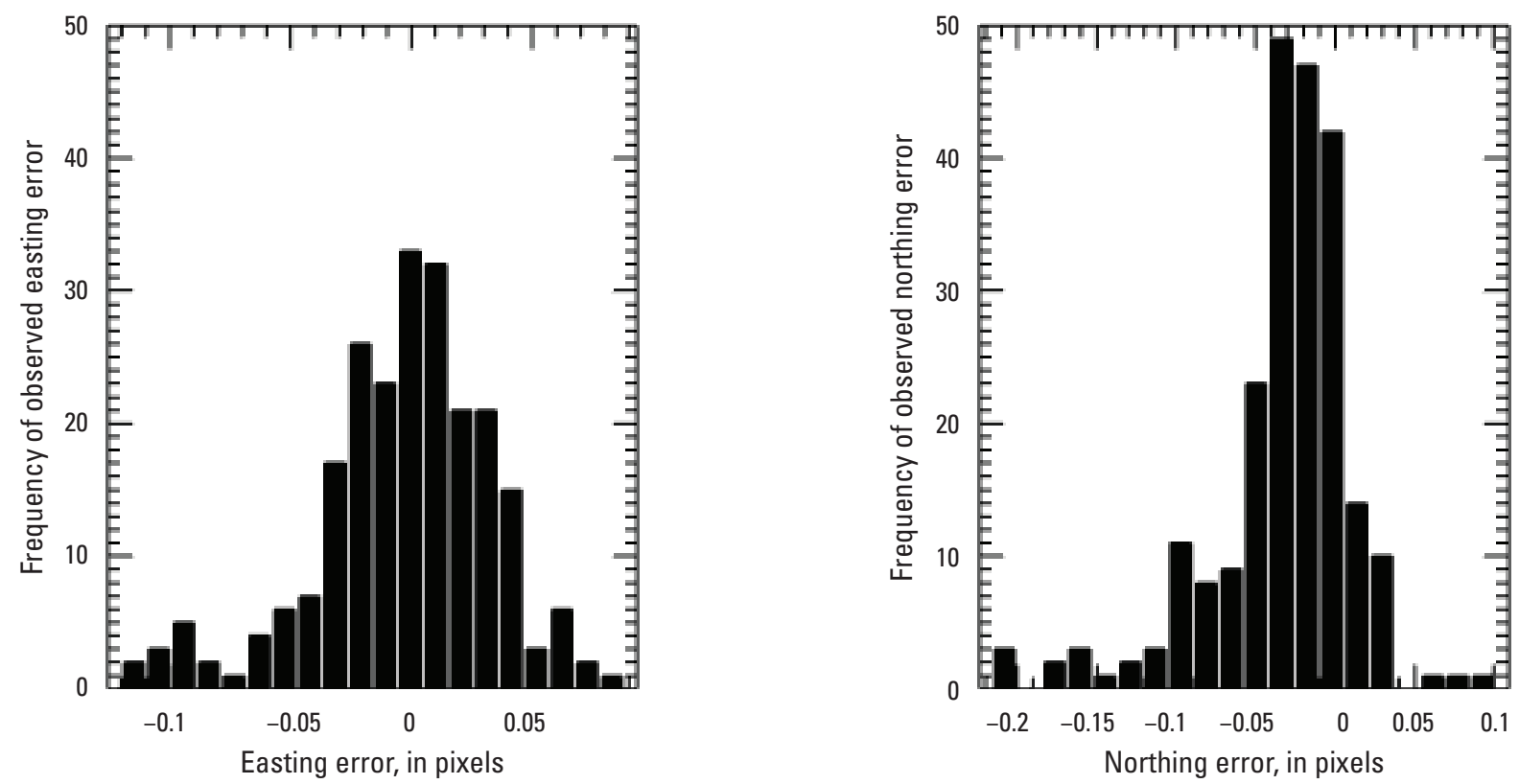

Figure 10. Band 1 (blue) to band 2 (green) geometric error histogram, Railroad Valley, Nevada.

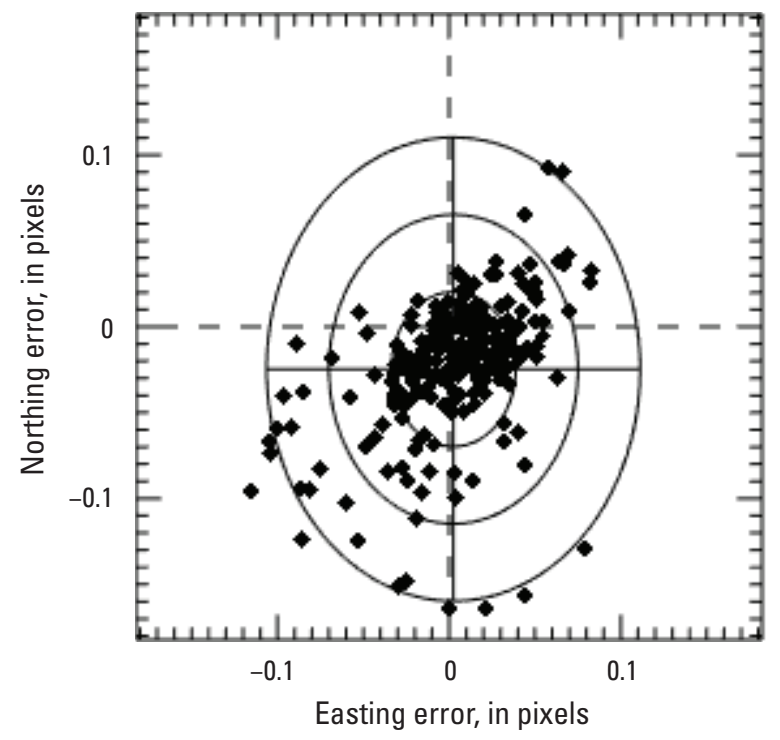

Figure 11. Band 1 (blue) to band 2 (green) geometric error plot, Railroad Valley, Nevada. 


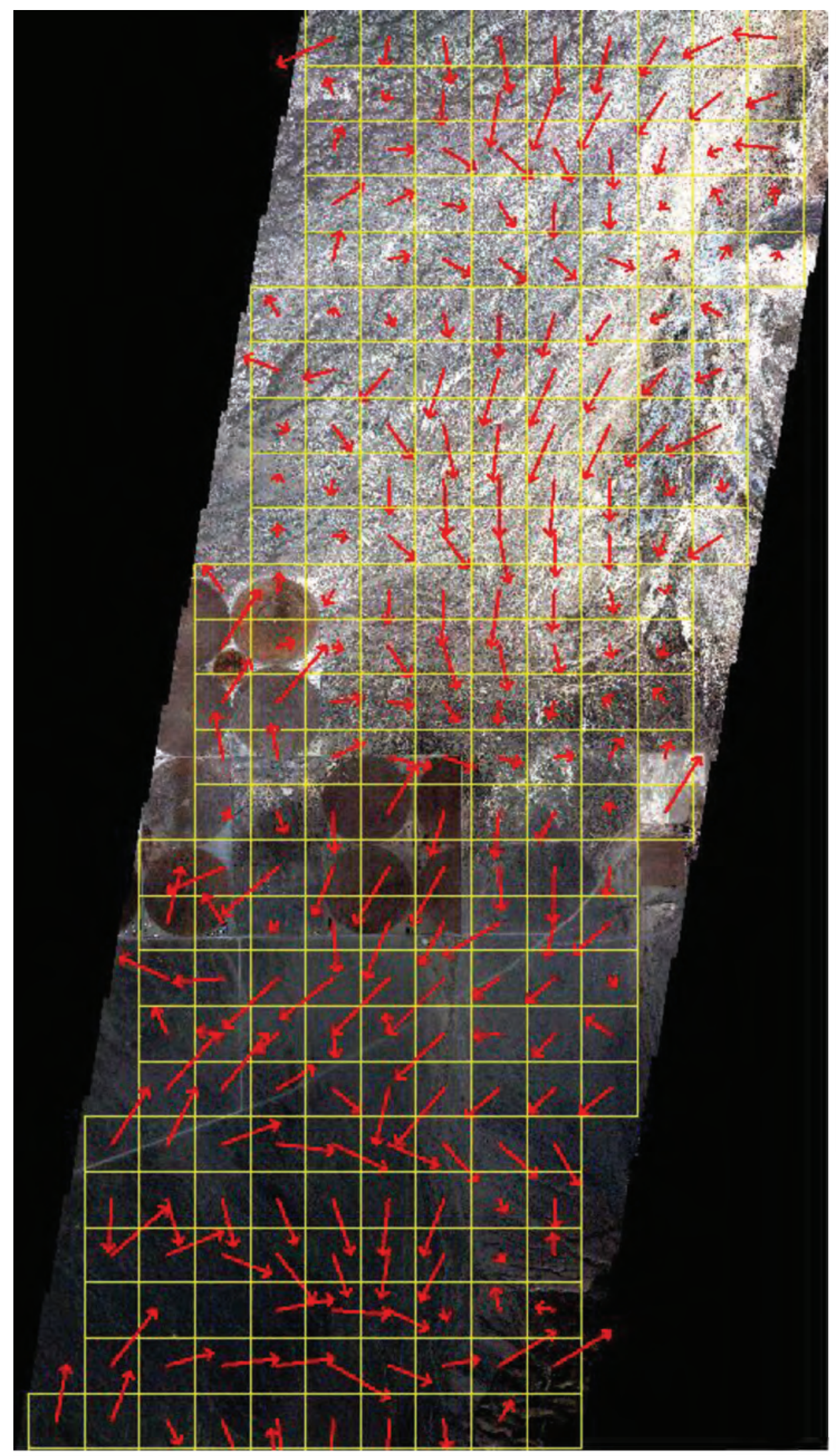

\section{EXPLANATION}

Easting and northing error Grid

Figure 12. Band 2 (green) to band 3 (red) geometric error map, Railroad Valley, Nevada. 


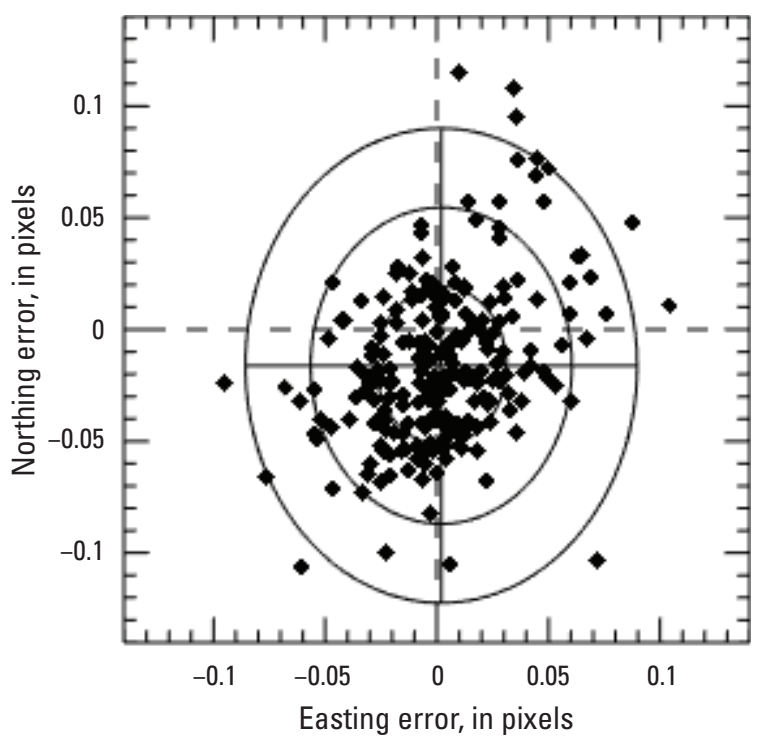

Figure 13. Band 2 (green) to band 3 (red) geometric error plot, Railroad Valley, Nevada. 


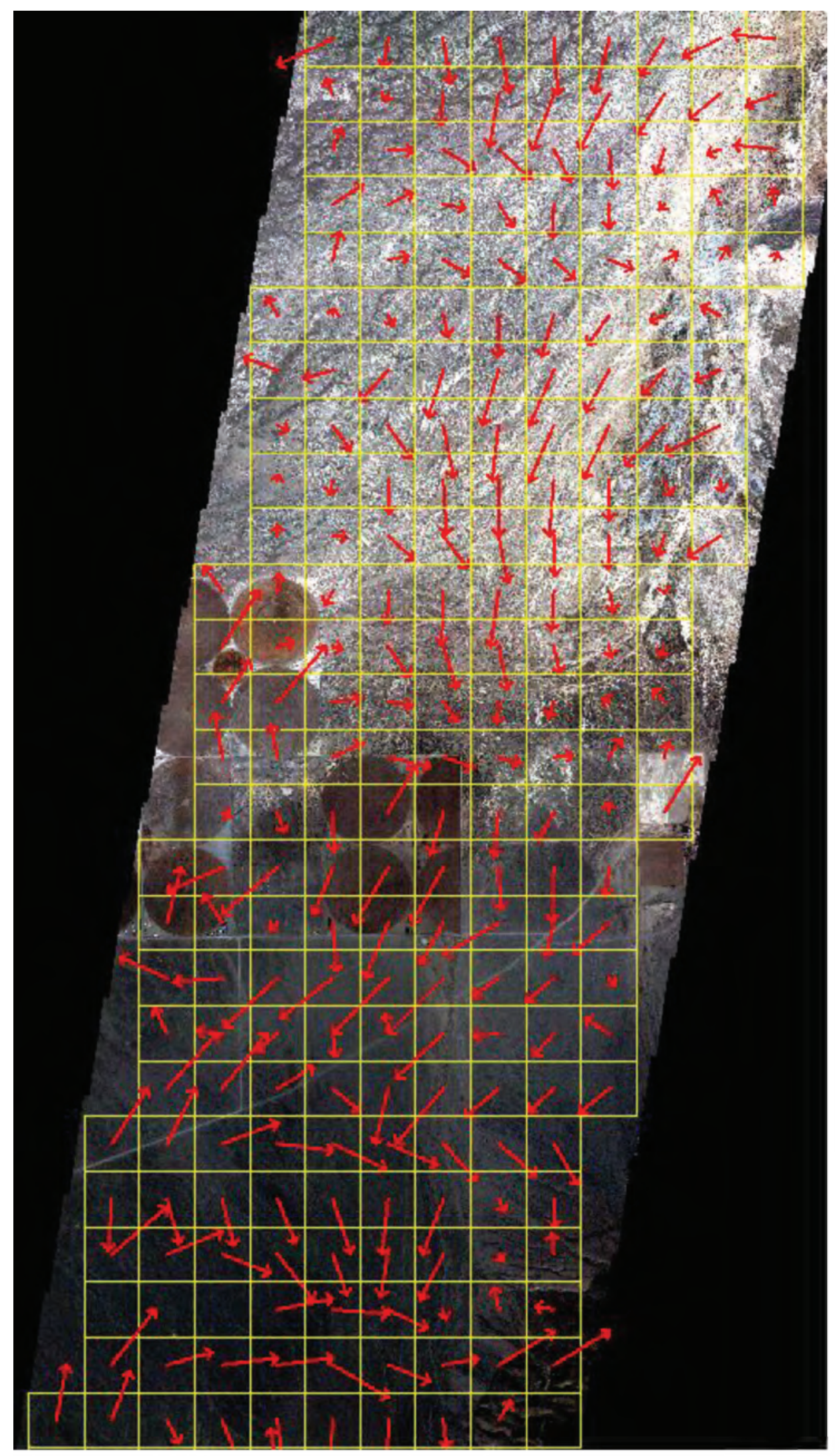

\section{EXPLANATION}

Easting and northing error Grid

Figure 14. Band 2 (green) to band 4 (near infrared) geometric error map, Railroad Valley, Nevada. 


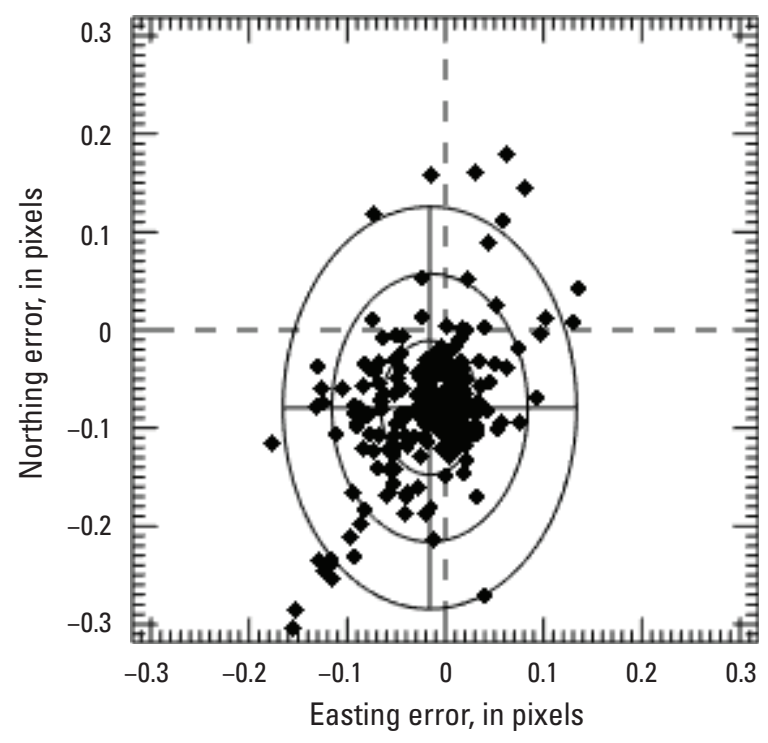

Figure 15. Band 2 (green) to band 4 (near infrared) geometric error plot, Railroad Valley, Nevada.

\section{Exterior (Geometric Location Accuracy)}

For this analysis, two procedures were used. In the first procedure, band 4 (near infrared) of two NewSat images was compared with the corresponding band from two Sentinel-2 images over Fès, Morocco, and Railroad Valley, Nev., using the Earth Resources Observation and Science System Characterization software. Conjugate points in the reference and search images were identified automatically and refined using similarity measures such as normalized cross-correlation metrics, and the mean error and root mean square error results are listed in table 5, in pixels at a 1-m GSD. For each of the two images, geometric error maps showing the directional shift and relative magnitude of the shift, when compared with Sentinel-2, are provided in figures 16 and 17 . The Sentinel-2 imagery had a control uncertainty of about $3.6 \mathrm{~m}$ (95 percent).
In the second external geometric location accuracy procedure, a NewSat image over Sioux Falls, S. Dak., was compared to previously collected GCPs. For this analysis, 23 GCPs over Sioux Falls, S. Dak., were manually measured on the Satellogic four-band orthorectified image using the QGIS software (formerly known as Quantum Geographic Information System software). The horizontal coordinates derived from the image were compared to the known horizontal coordinates of the GCPs. Error statistics are listed in table 6, and an error plot is shown in figure 18. The National Standard for Spatial Data Accuracy metric, which is a 95-percent circular error value, is $6.5 \mathrm{~m}$.

Table 5. Geometric error of Satellogic's NewSat relative to Sentinel-2 imagery.

[ID, identifier; RMSE, root mean square error; $\mathrm{m}$, meter]

\begin{tabular}{|c|c|c|c|c|}
\hline Scene ID & $\begin{array}{c}\text { Mean error } \\
\text { (easting) }\end{array}$ & $\begin{array}{l}\text { Mean error } \\
\text { (northing) }\end{array}$ & $\begin{array}{c}\text { RMSE } \\
\text { (easting) }\end{array}$ & $\begin{array}{c}\text { RMSE } \\
\text { (northing) }\end{array}$ \\
\hline $\begin{array}{l}\text { 20210423_110441_SN10_L1_Full } \\
\text { S2B_MSIL1C_20210423T105619_N0300_ } \\
\text { R094_T30STC_20210423T115904 (Fès, } \\
\text { Morocco) }\end{array}$ & $\begin{array}{r}-5.84 \text { pixels } \\
(-5.84 \mathrm{~m})\end{array}$ & $\begin{array}{r}1.25 \text { pixels } \\
(1.25 \mathrm{~m})\end{array}$ & $\begin{array}{r}6.05 \text { pixels } \\
(6.05 \mathrm{~m})\end{array}$ & $\begin{array}{r}2.52 \text { pixels } \\
(2.52 \mathrm{~m})\end{array}$ \\
\hline $\begin{array}{l}\text { 20210228_183201_SN10_L1_Full } \\
\text { L1C_T11SPC_A029725_20210301T183130 } \\
\text { (Railroad Valley, Nevada) }\end{array}$ & $\begin{array}{r}-9.04 \text { pixels } \\
(-9.04 \mathrm{~m})\end{array}$ & $\begin{array}{r}3.11 \text { pixels } \\
(3.11 \mathrm{~m})\end{array}$ & $\begin{array}{r}9.30 \text { pixels } \\
(9.30 \mathrm{~m})\end{array}$ & $\begin{array}{r}5.87 \text { pixels } \\
(5.87 \mathrm{~m})\end{array}$ \\
\hline
\end{tabular}




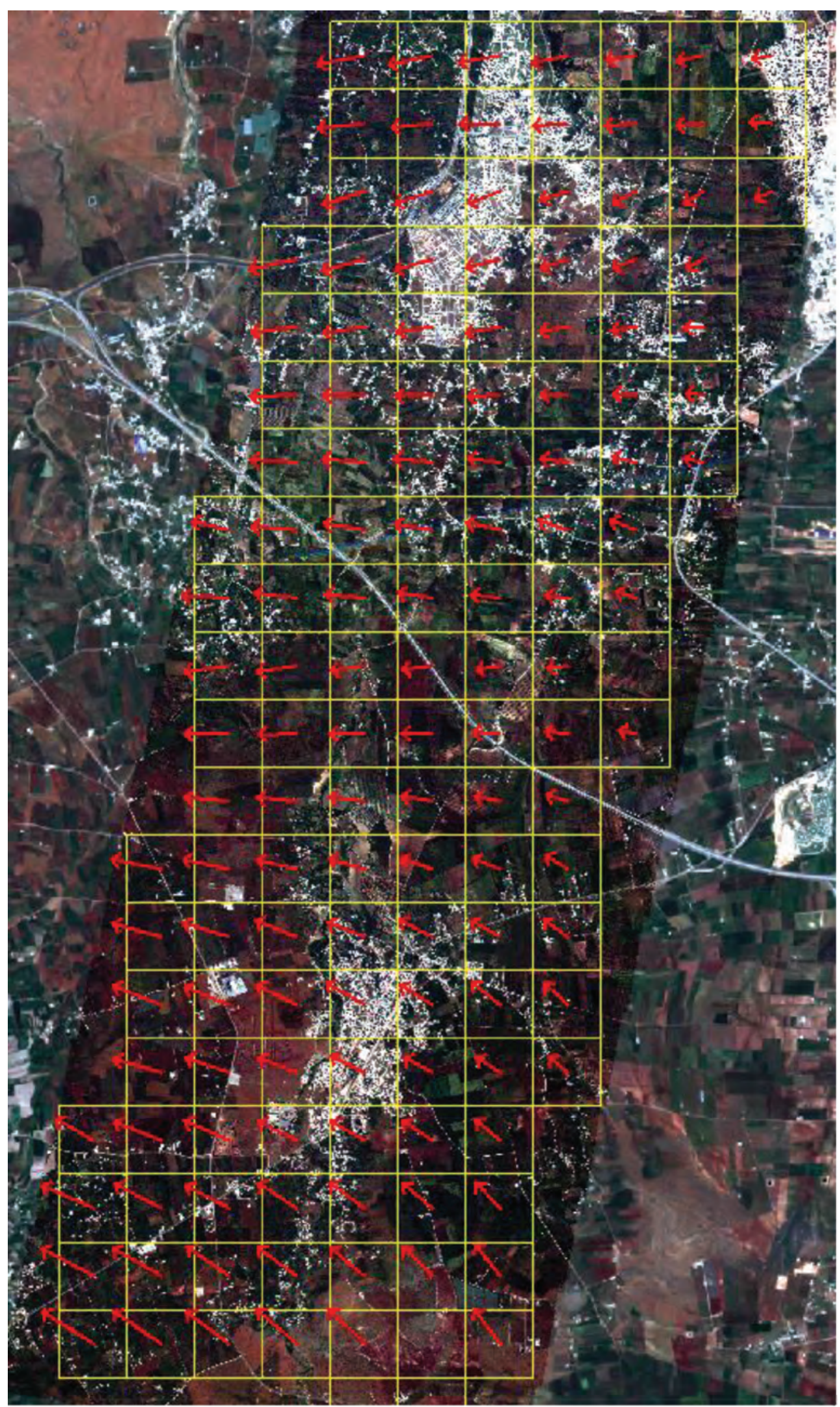

\section{EXPLANATION}

Easting and northing error Grid

Figure 16. Relative geometric error comparison for Satellogic's NewSat and Sentinel-2, Fès, Morocco. 


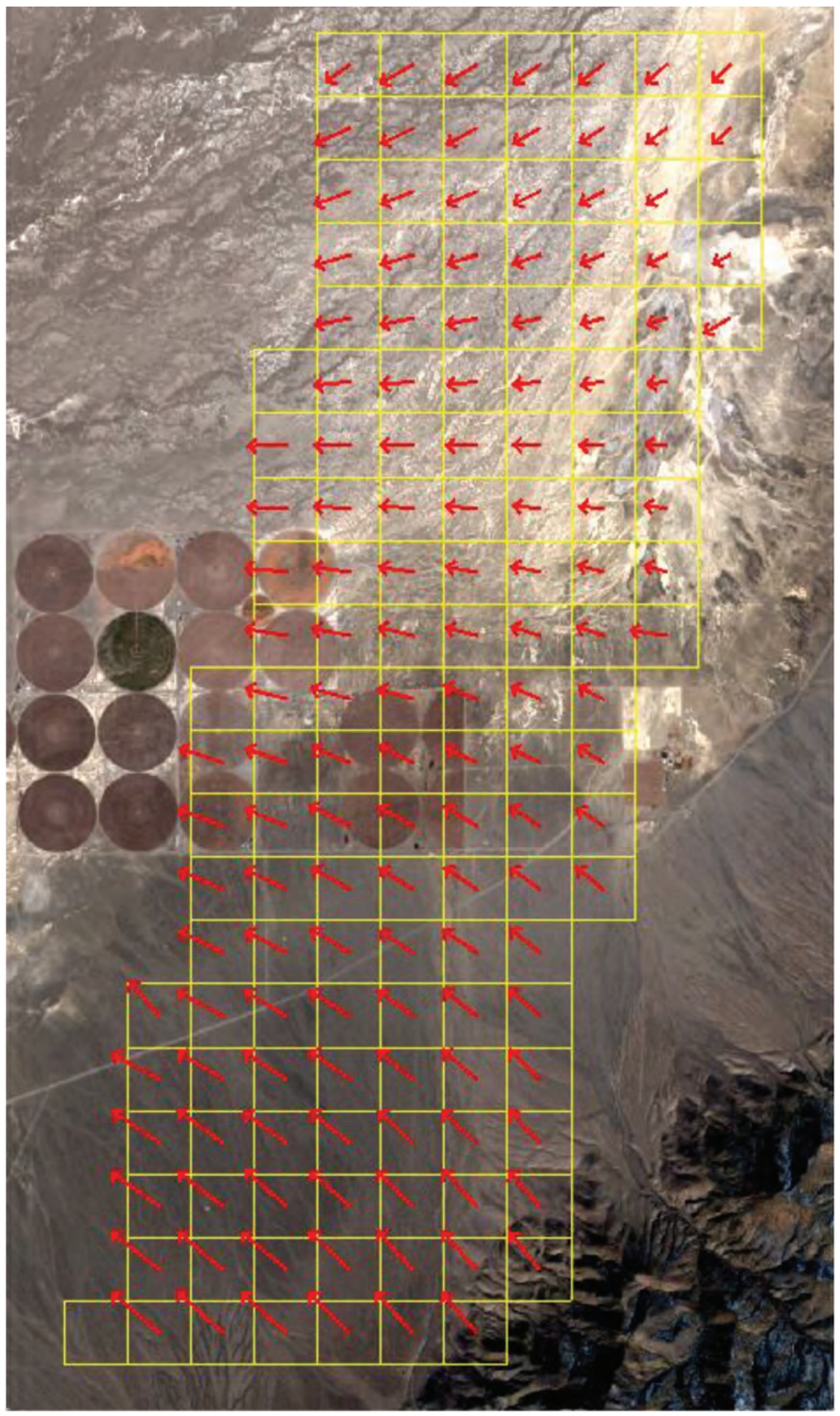

\section{EXPLANATION}

$\longrightarrow \quad$ Easting and northing error Grid

Figure 17. Relative geometric error comparison for Satellogic's NewSat and Sentinel-2, Railroad Valley, Nevada. 
Table 6. Geometric error of Satellogic's NewSat orthorectified image relative to ground control points.

[ID, identifier; SDDEV, standard deviation; RMSE, root mean square error; NSSDA, National Standard for Spatial Data Accuracy; \%, percent; m, meter]

\begin{tabular}{lrrrrrrr}
\hline \multicolumn{1}{c}{ Scene ID } & $\begin{array}{c}\text { Mean error } \\
\text { (easting) }\end{array}$ & $\begin{array}{c}\text { Mean error } \\
\text { (northing) }\end{array}$ & $\begin{array}{c}\text { SDDEV error } \\
\text { (easting) }\end{array}$ & $\begin{array}{c}\text { SDDEV error } \\
\text { (northing) }\end{array}$ & $\begin{array}{c}\text { RMSE error } \\
\text { (easting) }\end{array}$ & $\begin{array}{c}\text { RMSE error } \\
\text { (northing) }\end{array}$ & $\begin{array}{c}\text { NSSDA } \\
\text { (95\%) }\end{array}$ \\
\hline 20210509_171929_- & 0.46 pixel & -0.49 pixel & 3.1 pixels & 2.1 pixels & 3.1 pixels & 2.1 pixels & 6.5 pixels \\
SN10_L1_Full (Sioux & $(0.46 \mathrm{~m})$ & $(-0.49 \mathrm{~m})$ & $(3.1 \mathrm{~m})$ & $(2.1 \mathrm{~m})$ & $(3.1 \mathrm{~m})$ & $(2.1 \mathrm{~m})$ & $(6.5 \mathrm{~m})$ \\
Falls, South Dakota) & & & & & & & \\
\hline
\end{tabular}

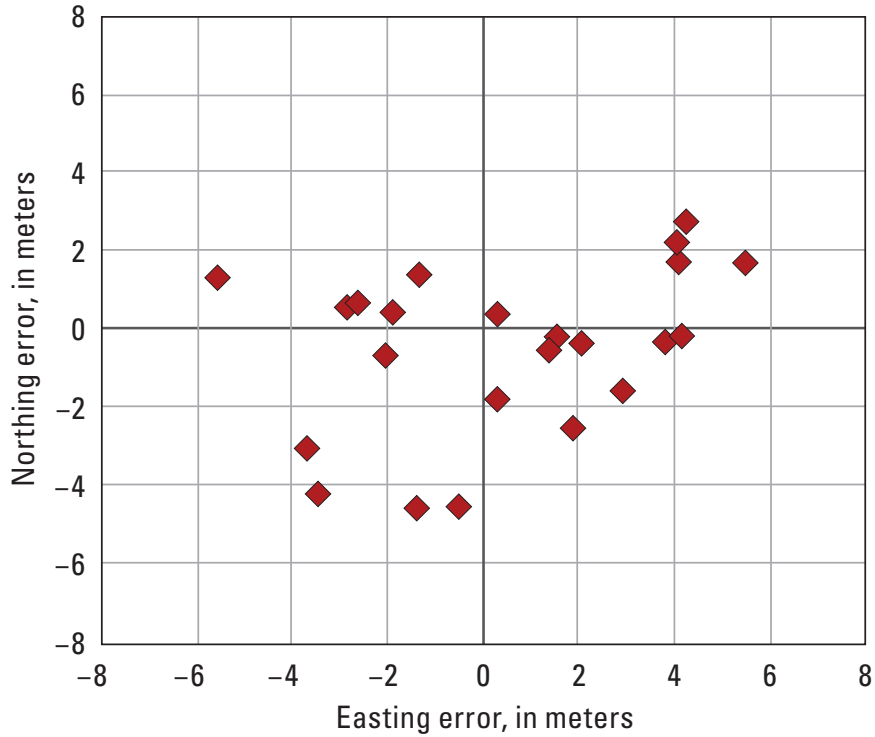

EXPLANATION

\section{Easting and northing error}

Figure 18. Satellogic's NewSat geometric error plot showing horizontal geolocation accuracy, Sioux Falls, South Dakota.

\section{Radiometric Performance}

For this analysis, cloud-free regions of interest were selected within two near-coincident Satellogic NewSat and Sentinel-2 scene pairs. Once the relative georeferencing error between Sentinel-2 and Satellogic's NewSat has been corrected, Top of Atmosphere reflectance values from the two sensors are extracted. The scatterplots (figs. 19 and 20) are drawn in a way that the $\mathrm{x}$-axis is the reference sensor and the $y$-axis is the comparison sensor. The linear regression, thus, represents Top of Atmosphere reflectance relative to that of the reference sensor. Ideally, the slope should be near unity, and the offset should be near zero. For instance, if the slope is greater than unity, that means the comparison sensor has a tendency to overestimate Top of Atmosphere reflectance compared to the reference sensor.

Top of Atmosphere reflectance comparison results are listed in table 7. A band-by-band graphical comparison between the NewSat image over Fès, Morocco, when compared with the corresponding Sentinel-2 band is shown in figure 19. A band-by-band comparison for the image over Railroad Valley, Nev., is shown in figure 20. 


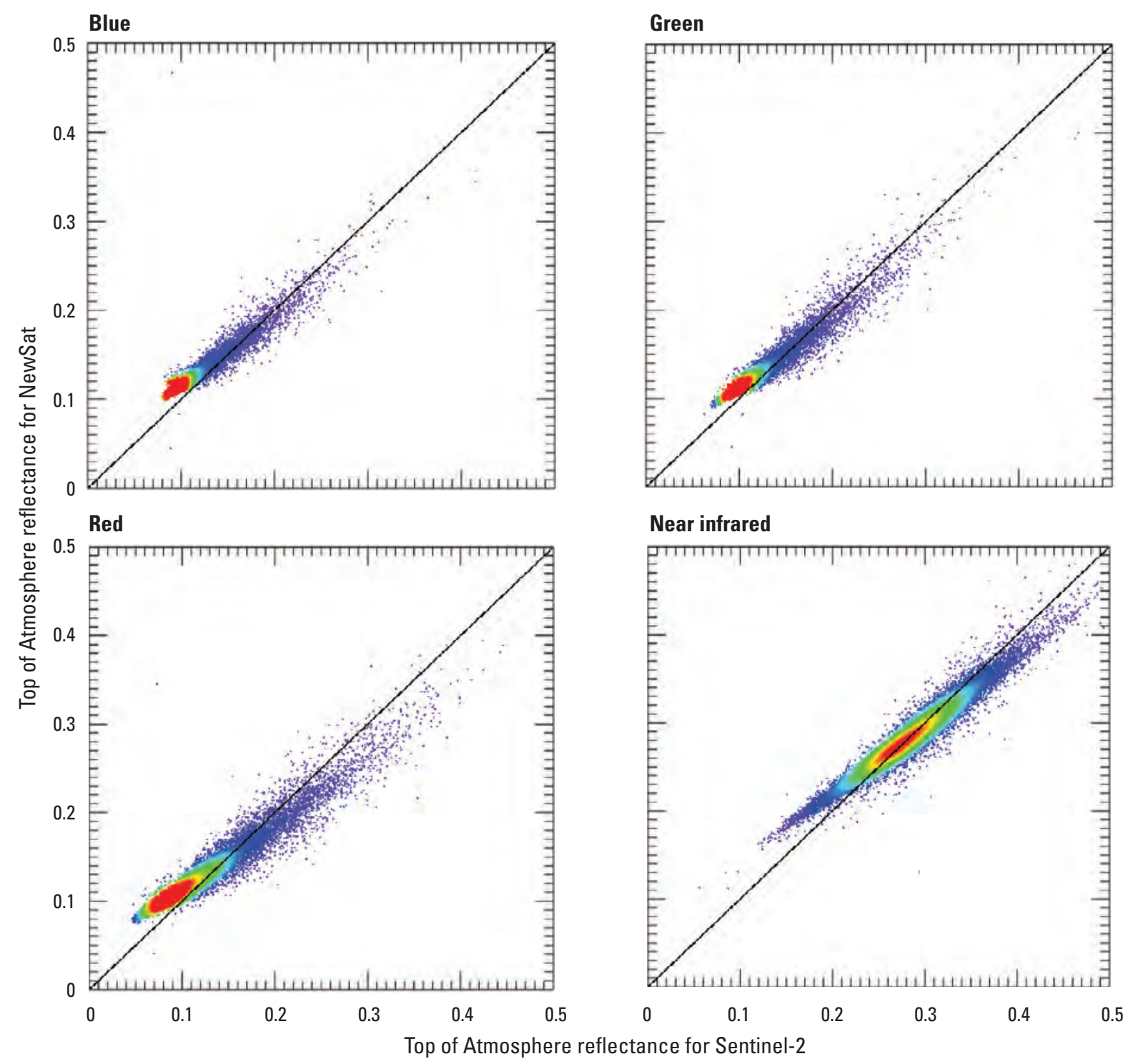

Figure 19. Top of Atmosphere reflectance comparison for Sentinel-2 and Satellogic's NewSat images, Fès, Morocco. 


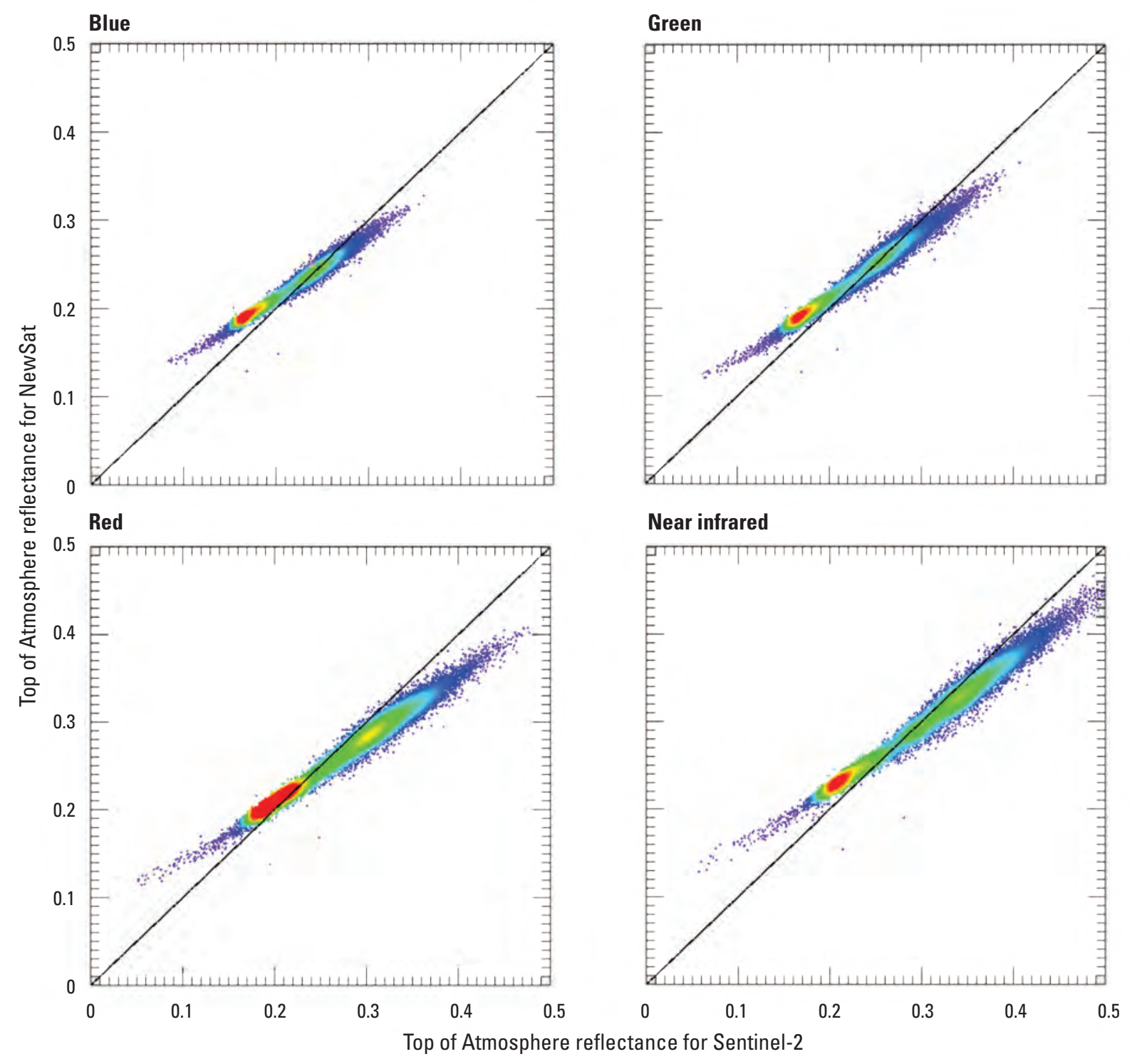

Figure 20. Top of Atmosphere reflectance comparison for Sentinel-2 and Satellogic's NewSat images, Railroad Valley, Nevada. 
Table 7. Top of Atmosphere reflectance comparison for Sentinel-2 against Satellogic's NewSat.

[ID, identifier; NIR, near infrared; \%, percent; $R^{2}$, coefficient of determination]

\begin{tabular}{llllll}
\hline \multicolumn{1}{c}{ Scene ID } & \multicolumn{1}{c}{ Statistics } & $\begin{array}{c}\text { Band 1 } \\
\text { (blue) }\end{array}$ & $\begin{array}{c}\text { Band 2 } \\
\text { (green) }\end{array}$ & $\begin{array}{c}\text { Band 3 } \\
\text { (red) }\end{array}$ & $\begin{array}{c}\text { Band 4 } \\
\text { (NIR) }\end{array}$ \\
\hline 20210423_110441_SN10_L1_Full & Uncertainty (\%) & 5.48 & 6.04 & 10.72 & 4.05 \\
S2B_MSIL1C_20210423T105619_N0300_ & $R^{2}$ & 0.932 & 0.935 & 0.936 & 0.943 \\
R094_T30STC_20210423T115904 & Regression offset & 0.041 & 0.034 & 0.041 & 0.054 \\
(Fès, Morocco) & Regression slope & 0.754 & 0.783 & 0.727 & 0.808 \\
& Uncertainty (\%) & 2.65 & 2.89 & 3.12 & 2.81 \\
20210228_183201_SN10_L1_Full & $R^{2}$ & 0.874 & 0.885 & 0.886 & 0.895 \\
S2A_MSIL1C_20210301T182301_N0209_- & Regression offset & 0.081 & 0.071 & 0.074 & 0.075 \\
R127_T11SPC_20210301T203801 & Regression slope & 0.652 & 0.703 & 0.679 & 0.725 \\
(Railroad Valley, Nevada) & & & & & \\
\end{tabular}

\section{Spatial Performance}

For this analysis, edge spread and line spread functions were calculated with resulting full width at half maximum and modulation transfer function at Nyquist frequency analysis outputs, as listed in table 8. The Satellogic NewSat image used for the analysis is "20210502_033103_SN10_L1_Full. tif" for Baotou, China (fig. 21), and includes the edge transect bounding box. The results for band 1 (blue) are shown in figures 22 and 23. In figure 22, the raw transects, the middle transect, and the region of the curve that is used for alignment

Table 8. Spatial performance of Satellogic's NewSat.

[RER, relative edge response; FWHM, full width at half maximum; MTF, modulation transfer function; NIR, near infrared]

\begin{tabular}{lccc}
\hline \multicolumn{1}{c}{ Spatial analysis } & RER & FWHM & $\begin{array}{c}\text { MTF at } \\
\text { Nyquist }\end{array}$ \\
\hline Band 1-blue & 0.62 & 1.61 pixels & 0.138 \\
Band 2 - green & 0.56 & 1.64 pixels & 0.115 \\
Band 3 - red & 0.53 & 1.63 pixels & 0.110 \\
Band 4-NIR & 0.41 & 1.76 pixels & 0.081 \\
\hline
\end{tabular}

are shown in the upper plot. The lower plot in figure 22 shows the aligned transect and the edge spread function. The upper plot in figure 23 shows an edge spread function with the relative edge response and a line spread function with a line segment representing full width at half maximum. The lower plot in figure 23 shows a modulation transfer function up to Nyquist frequency $(0.5)$ and the frequency corresponding to the 50-percent modulation transfer function value. The results for band 2 (green) are shown in figures 24 and 25, the results for band 3 (red) are shown in figures 26 and 27, and the results for band 4 (near infrared) are shown in figures 28 and 29.

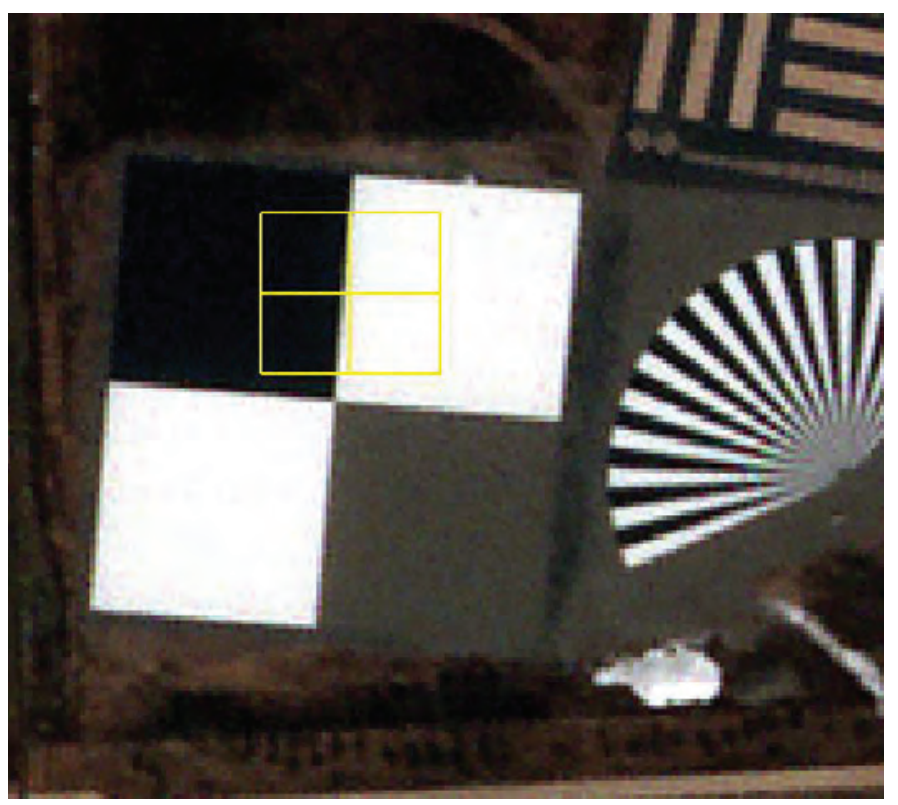

\section{EXPLANATION}

Edge transect bounding box

Figure 21. Satellogic NewSat image of calibration site at Baotou, China. 

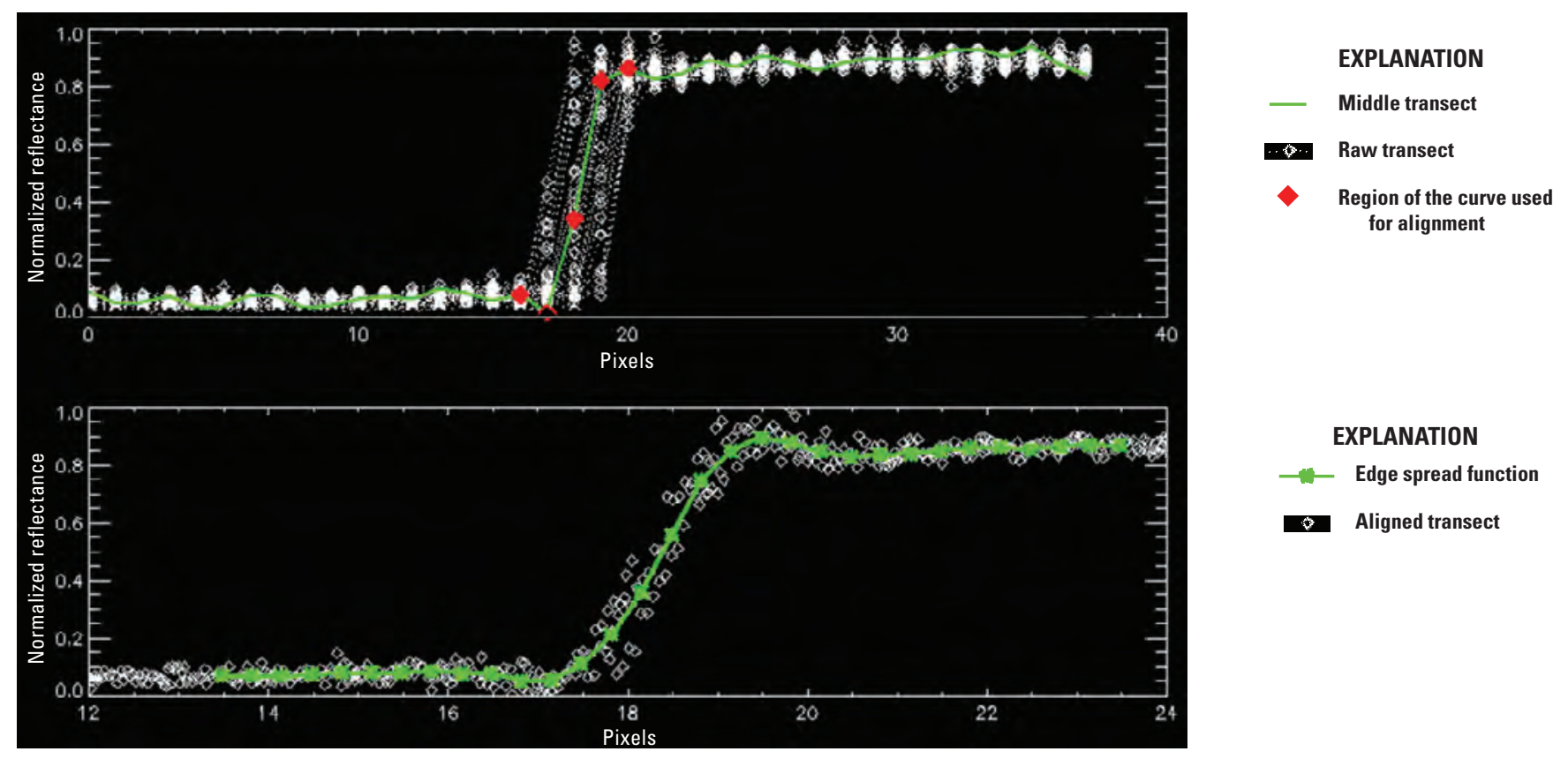

Figure 22. Band 1 (blue) raw edge transects (upper) and shifted transects (lower) at Baotou, China.
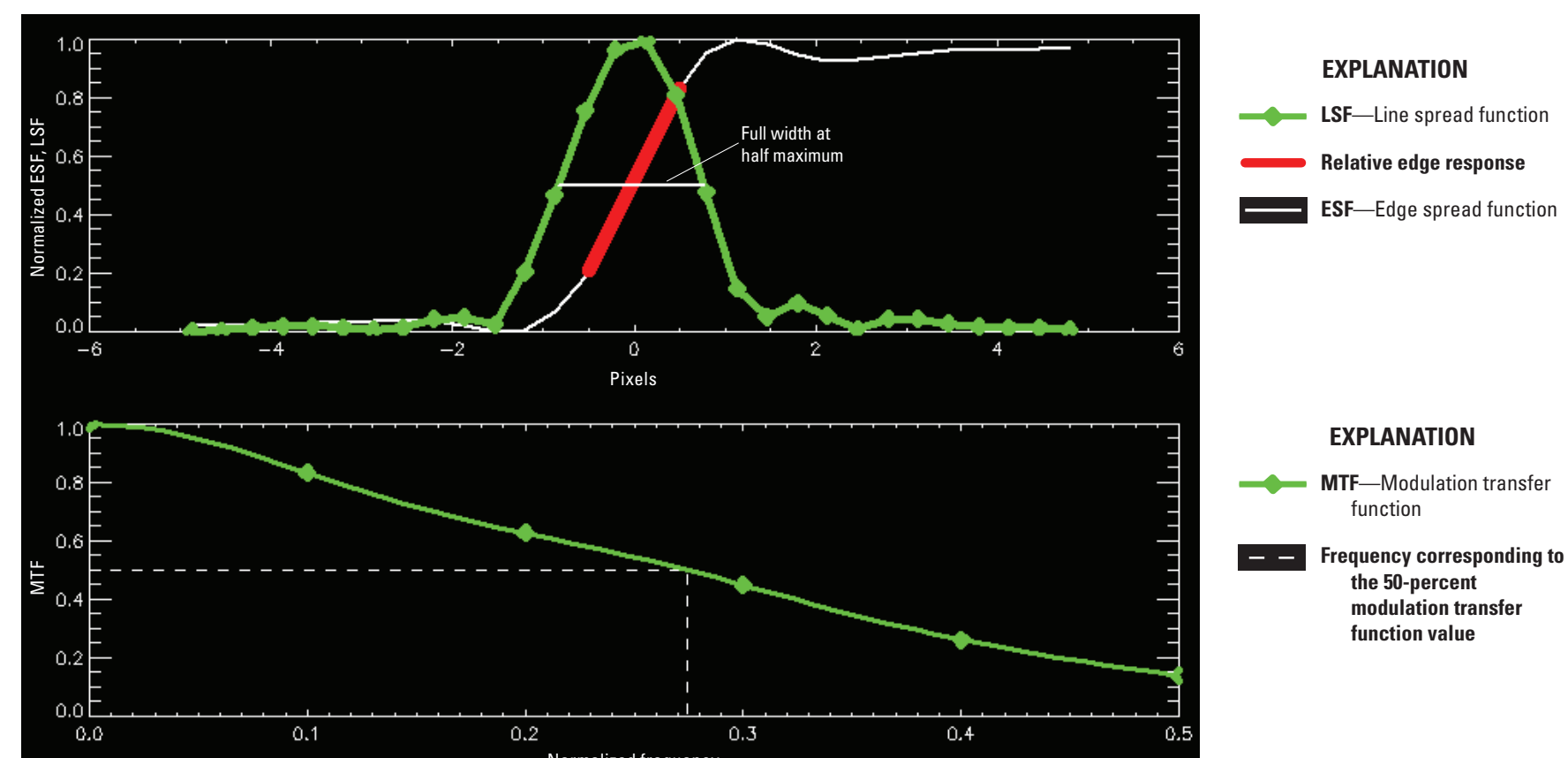

\section{EXPLANATION}

MTF-Modulation transfer function

Frequency corresponding to the 50-percent modulation transfer function value

Figure 23. Band 1 (blue) edge spread function and line spread function (upper) and modulation transfer function (lower) at Baotou, China. 

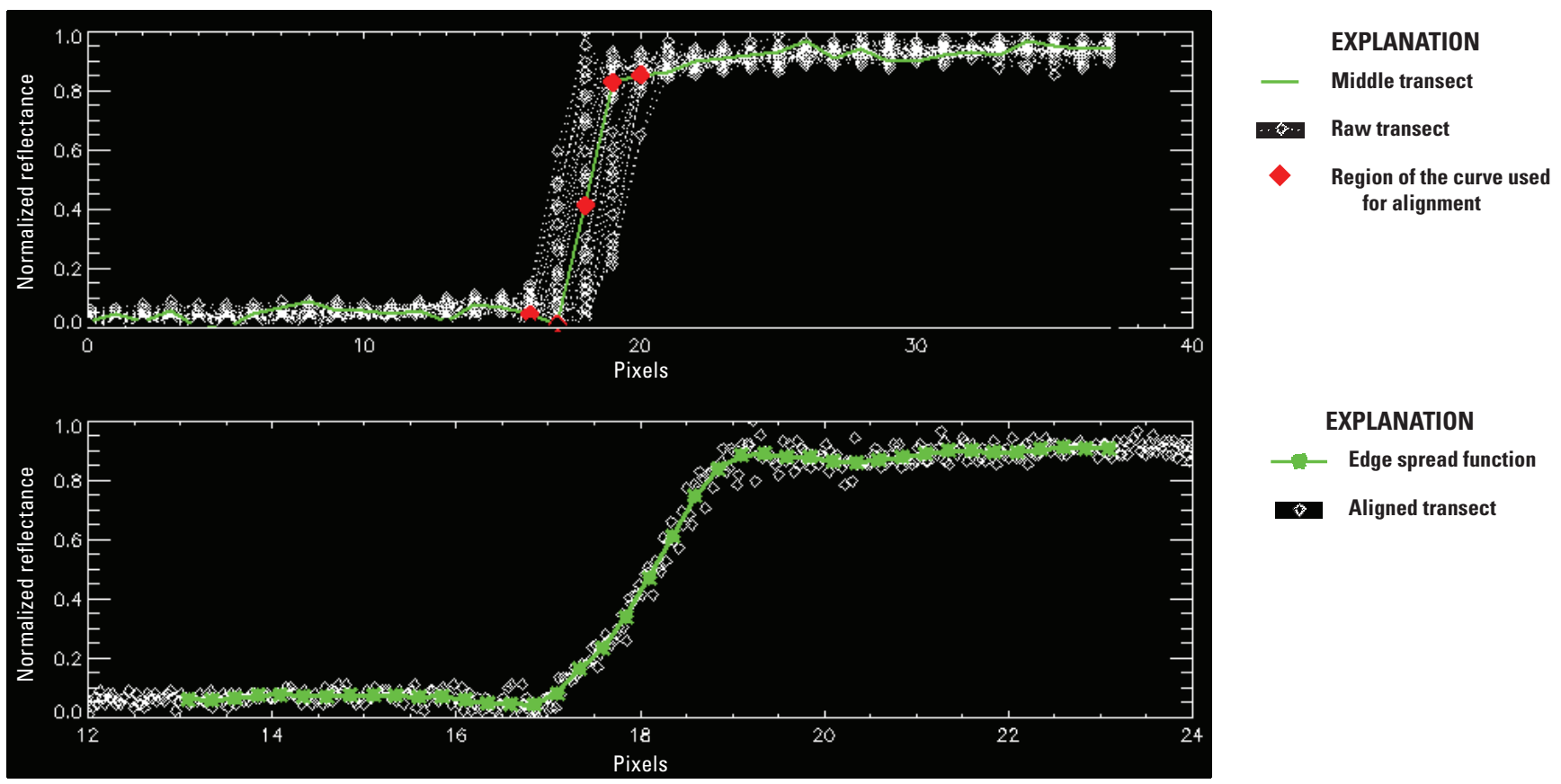

- Edge spread function

Aligned transect

Figure 24. Band 2 (green) raw edge transects (upper) and shifted transects (lower) at Baotou, China.
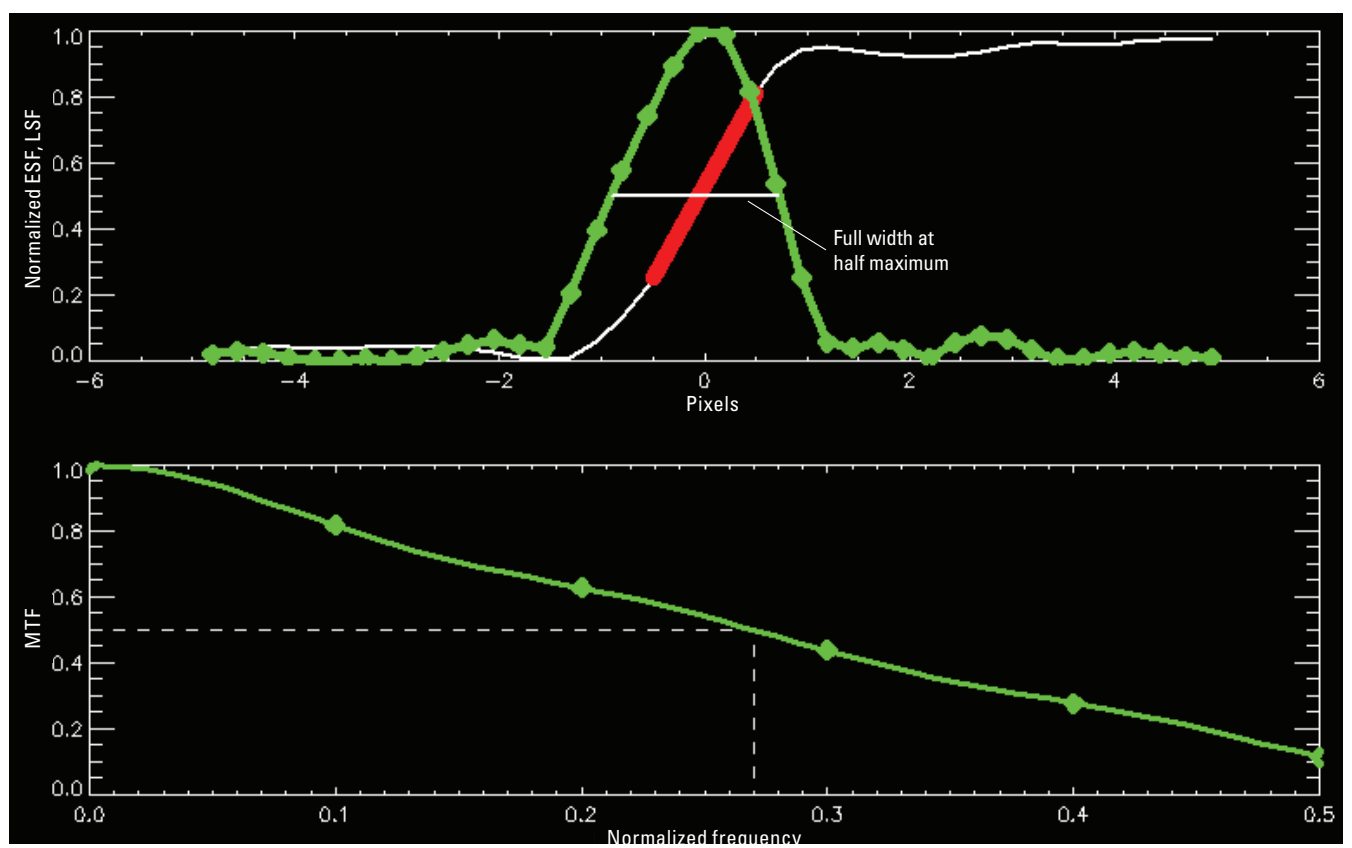

\section{EXPLANATION}

- LSF-Line spread function

Relative edge response

ESF-Edge spread function

\section{EXPLANATION}

- MTF-Modulation transfer function

Frequency corresponding to

the 50-percent

modulation transfer

function value

Figure 25. Band 2 (green) edge spread function and line spread function (upper) and modulation transfer function (lower) at Baotou, China. 


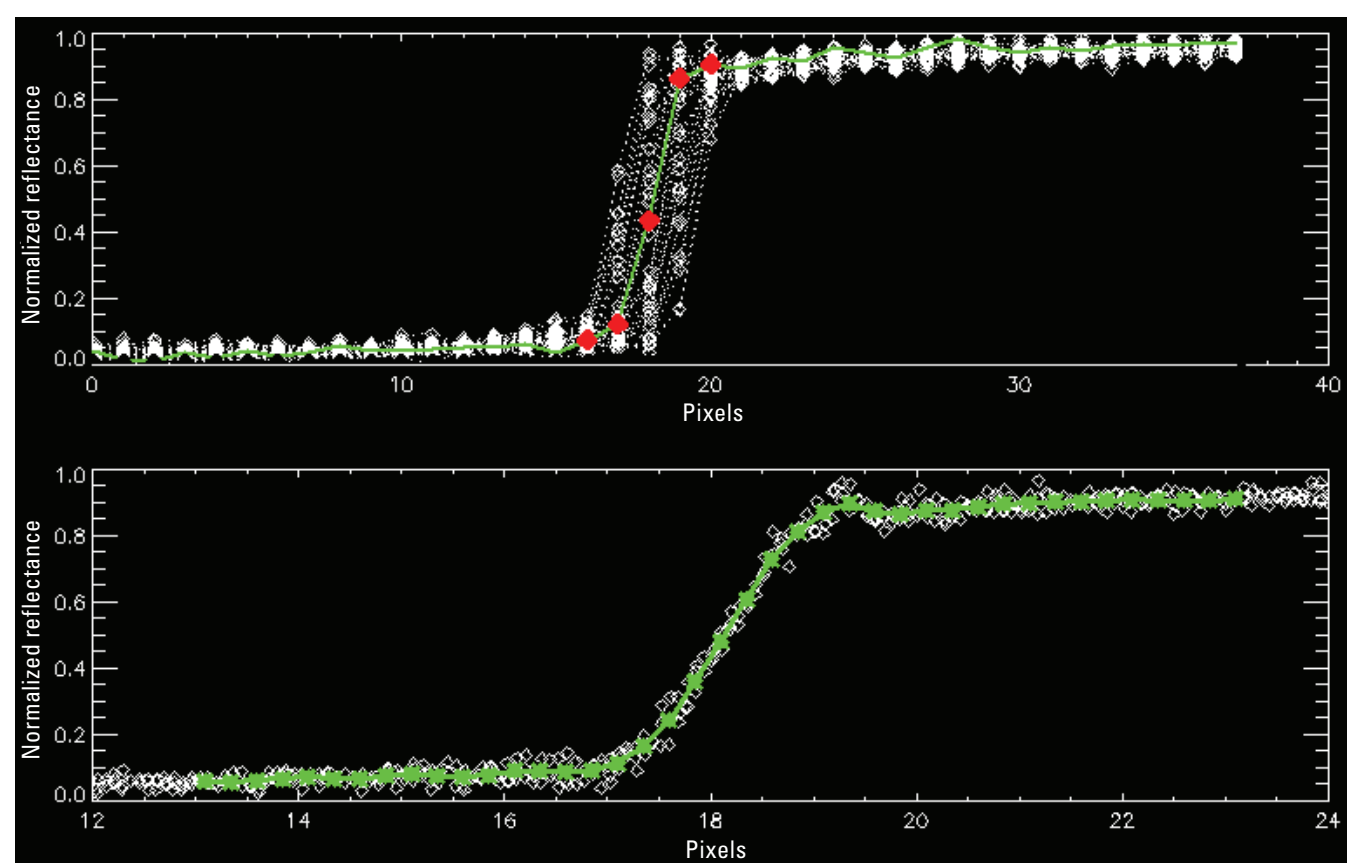

\section{EXPLANATION}

- Middle transect

B.. Raw transect

Region of the curve used for alignment

\section{EXPLANATION}

- - Edge spread function

Aligned transect

Figure 26. Band 3 (red) raw edge transects (upper) and shifted transects (lower) at Baotou, China.

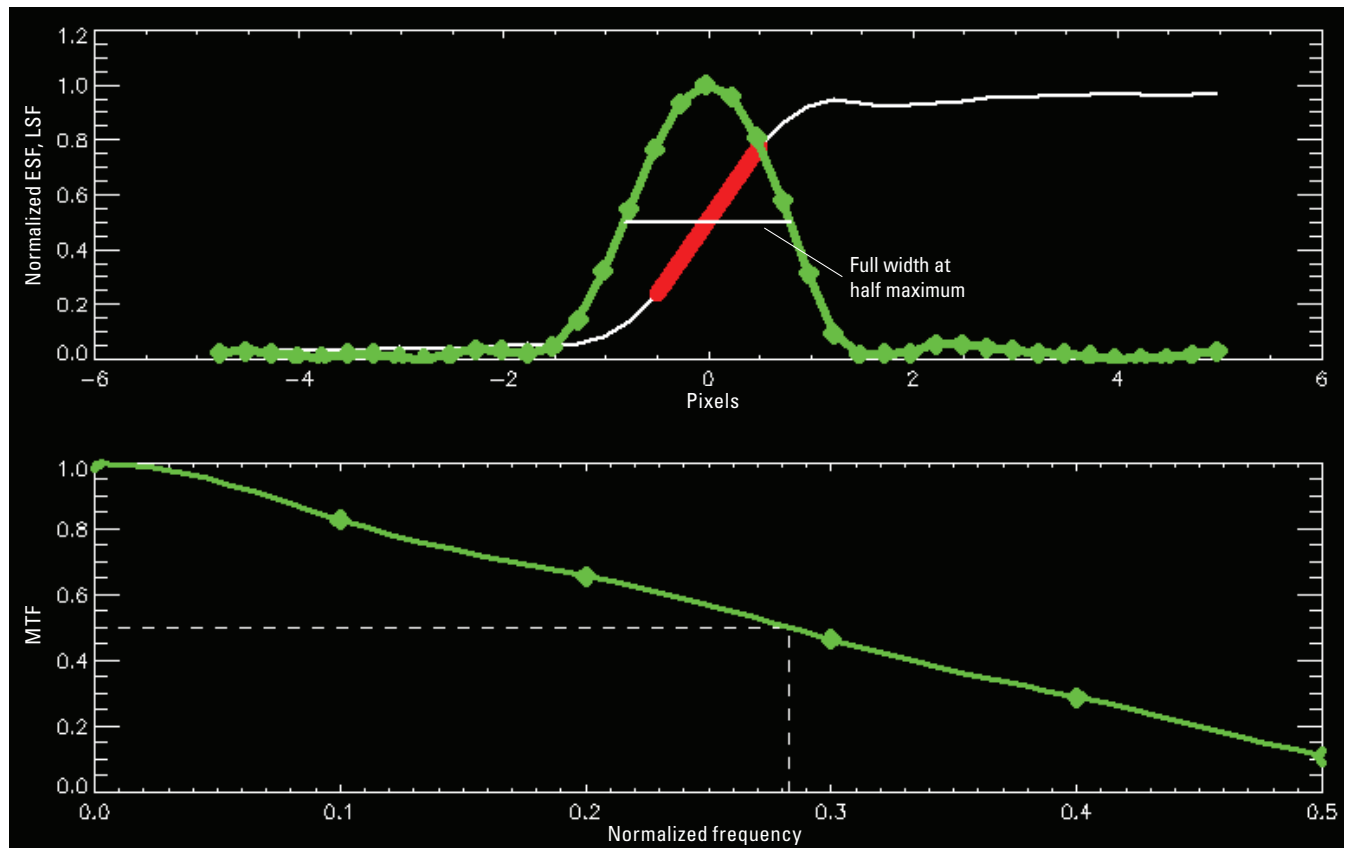

\section{EXPLANATION}

LSF-Line spread function

Relative edge response

ESF-Edge spread function

\section{EXPLANATION}

MTF-Modulation transfer function

Frequency corresponding to the 50-percent modulation transfer function value

Figure 27. Band 3 (red) edge spread function and line spread function (upper) and modulation transfer function (lower) at Baotou, China. 


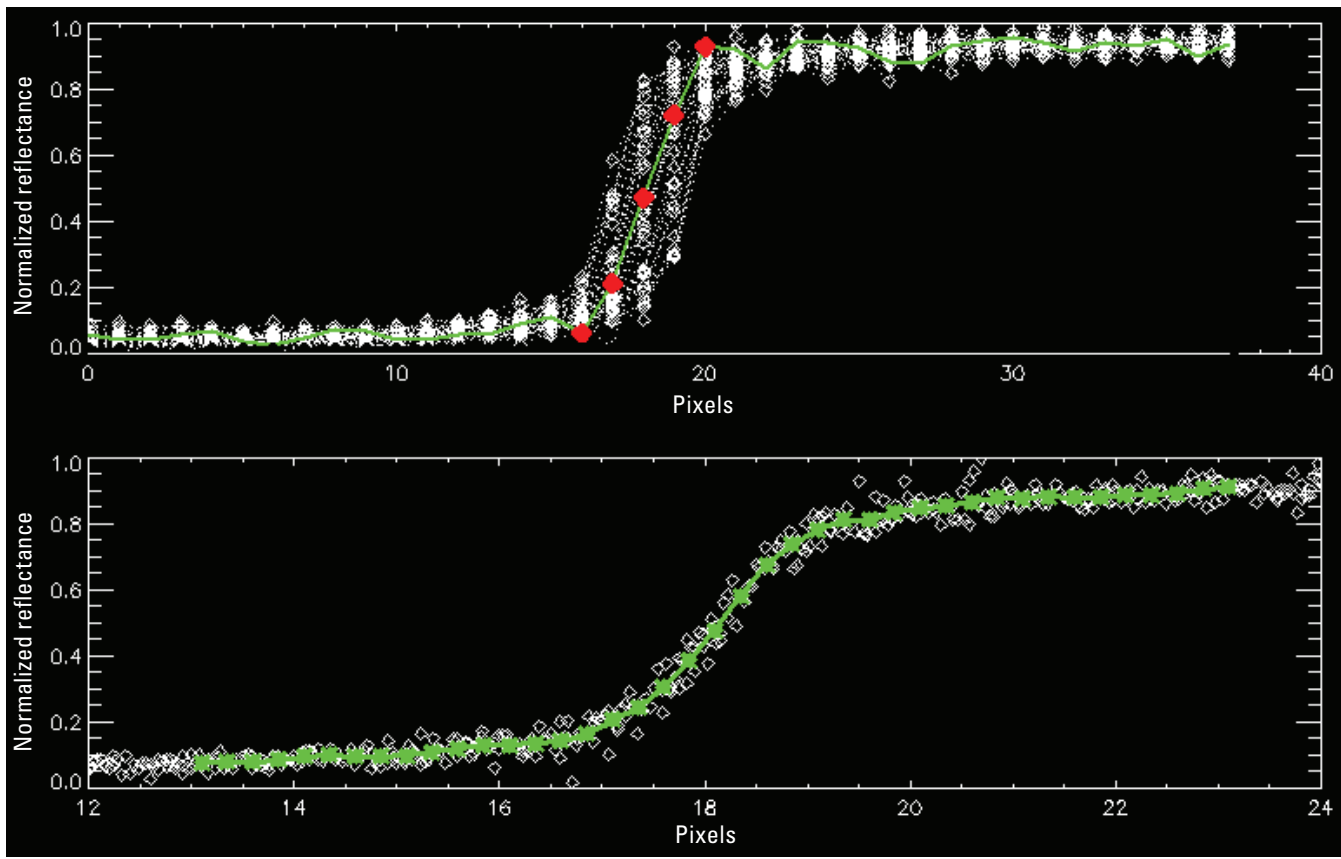

\section{EXPLANATION}

Middle transect

Raw transect

Region of the curve used for alignment

\section{EXPLANATION}

- Edge spread function

Figure 28. Band 4 (near infrared) raw edge transects (upper) and shifted transects (lower) at Baotou, China.

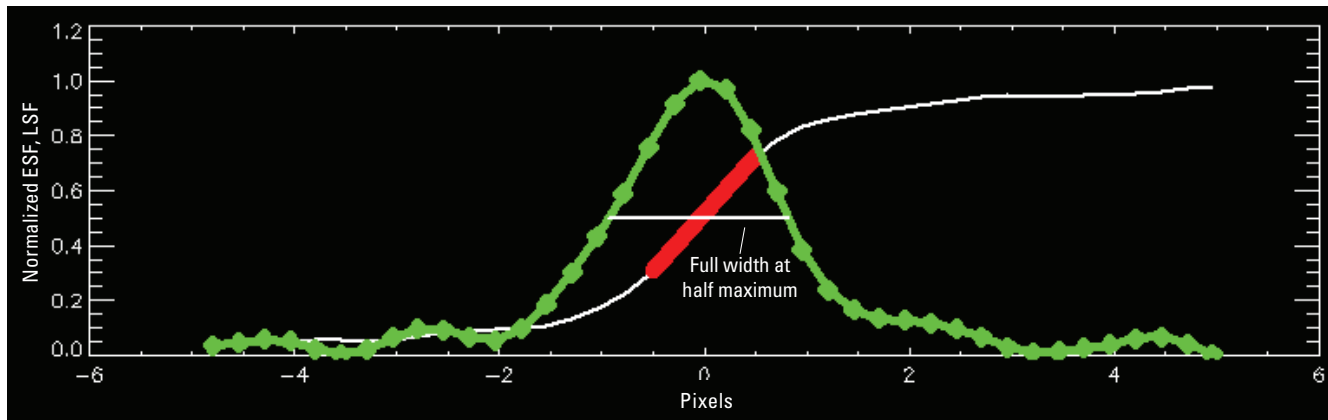

\section{EXPLANATION}

- LSF-Line spread function

Relative edge response

ESF-Edge spread function

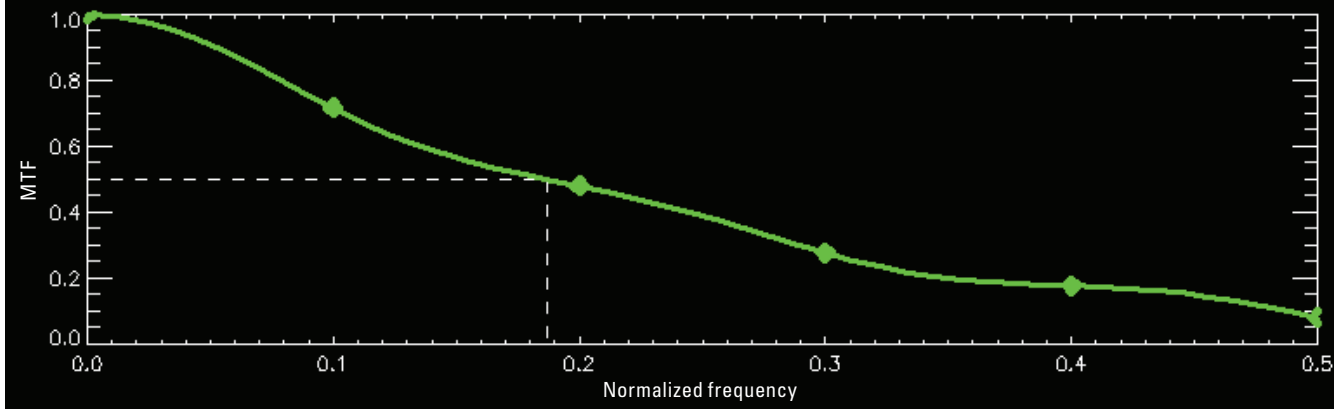

\section{EXPLANATION}

- MTF-Modulation transfer function

Frequency corresponding to the 50-percent modulation transfer function value

Figure 29. Band 4 (near infrared) edge spread function and line spread function (upper) and modulation transfer function (lower) at Baotou, China. 


\section{Summary and Conclusions}

This report summarizes the sensor performance of Satellogic's NewSat satellite sensing system based on the U.S. Geological Survey Earth Resources Observation and Science Cal/Val Center of Excellence (ECCOE) system characterization process. In summary, we have determined that this sensor provides an interior geometric performance in the range -0.119 ( -0.119 pixel) to 0.020 meter $(\mathrm{m} ; 0.020$ pixel $)$ in easting and $-0.148(-0.148$ pixel $)$ to $0.014 \mathrm{~m}(0.014$ pixel $)$ in northing in band-to-band registration, an exterior geometric performance of -9.04 ( -9.04 pixels) to $-5.84 \mathrm{~m}$ ( -5.84 pixels) in easting and 1.25 (1.25 pixels) to $3.11 \mathrm{~m}$ (3.11 pixels) in northing offset in comparison to Sentinel-2 (values in pixels are identical to values in meters because the sensor has a 1 -m ground sample distance), an exterior geometric performance using ground control points of a $6.5-\mathrm{m}$ circular error (95 percent), a radiometric performance in the range of 0.034 to 0.081 in offset and 0.652 to 0.808 in slope, and a spatial performance in the range of 1.61 to 1.76 pixels for full width at half maximum, with a modulation transfer function at a Nyquist frequency in the range of 0.081 to 0.138 .

In conclusion, the team has completed an ECCOE standardized system characterization of the Satellogic's NewSat satellite sensing system. Although the team followed characterization procedures that are standardized across the many sensors and sensing systems under evaluation, these procedures are customized to fit the individual sensor, as was done with the NewSat satellites. The team has acquired the data, defined proper testing methodologies, carried out comparative tests against specific references, recorded measurements, completed data analyses, and quantified sensor performance accordingly. The team also endeavored to retain all data, measurements, and methods. This is key to ensure that all data and measurements are archived and accessible and that the performance results are reproducible.
The ECCOE project and associated Joint Agency Commercial Imagery Evaluation partners are always interested in reviewing sensor and remote sensing application assessments and would like to see and discuss information on similar data and product assessments and reviews. If you would like to discuss system characterization with the U.S. Geological Survey ECCOE and (or) the Joint Agency Commercial Imagery Evaluation team, please email us at eccoe@usgs.gov.

\section{Selected References}

Ramaseri Chandra, S.N., Christopherson, J.B., and Casey, K.A., 2020, 2020 Joint Agency Commercial Imagery Evaluation-Remote sensing satellite compendium: U.S. Geological Survey Circular 1468 (ver. 1.1, October 2020), 253 p. [Also available at https://doi.org/10.3133/cir1468.] [Supersedes USGS Circular 1455.]

Satellogic, 2021, Satellogic - Creating searchable Earth: Satellogic web page, accessed December 2021 at https://satellogic.com/.

U.S. Geological Survey, 2020a, EROS CalVal Center of Excellence (ECCOE): U.S. Geological Survey web page, accessed March 2021 at https://www.usgs.gov/calval.

U.S. Geological Survey, 2020b, EROS CalVal Center of Excellence (ECCOE) —JACIE: U.S. Geological Survey web page, accessed December 2021 at https://www.usgs.gov/ core-science-systems/eros/calval/jacie?qt-science_support page_related_con=3\#qt-science_support_page_related_con.

U.S. Geological Survey, 2020c, Landsat missions - Glossary and acronyms: U.S. Geological Survey web page, accessed March 2021 at https://www.usgs.gov/core-science-systems/ nli/landsat/glossary-and-acronyms. 
For more information about this publication, contact: Director, USGS Earth Resources Observation and Science Center 47914 252nd Street

Sioux Falls, SD 57198

605-594-6151

For additional information, visit: https://www.usgs.gov/centers/eros

Publishing support provided by the

Lafayette and Rolla Publishing Service Centers 


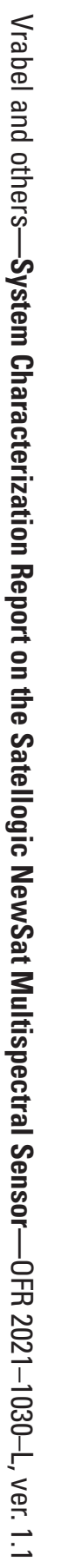

